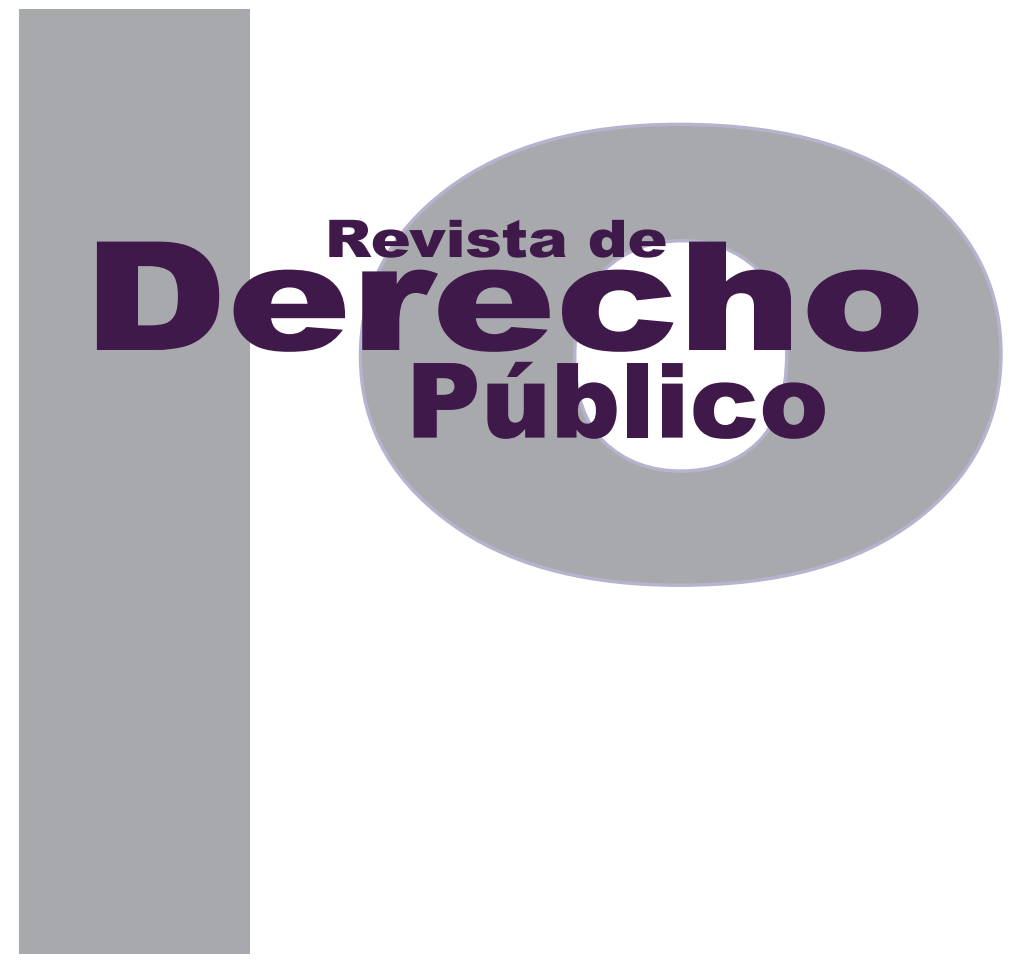

\title{
EL MATRIMONIO DE PAREJAS DEL MISMO SEXO EN EL SISTEMA INTERAMERICANO DE DERECHOS HUMANOS
}

\author{
MARÍA CeCILIA IbÁÑez García
}

Reporte de caso

Universidad de los Andes

Facultad de Derecho

Revista de Derecho Público N. ${ }^{\circ} 32$

Enero - Junio de 2014. ISSN 1909-7778 


\title{
El matrimonio de parejas del mismo sexo en el Sistema Interamericano de Derechos Humanos
}

\section{Resumen}

El debate sobre el derecho al matrimonio de parejas del mismo sexo ocurre también en el marco de los sistemas internacionales de derechos humanos. Debido a que dentro del Sistema Interamericano de Derechos Humanos aún no hay una postura al respecto, este artículo tiene como propósito predecir cuál podría ser la decisión de la Corte Interamericana de Derechos Humanos al enfrentarse a la materia. Para ello, se explicarán generalidades relevantes sobre el Sistema Interamericano y algunas técnicas interpretativas que suele usar la Corte Interamericana al fijar el alcance de Ios derechos convencionales. Además, se hará referencia a un caso en que el Tribunal Europeo de Derechos Humanos restringió el derecho al matrimonio solo para parejas heterosexuales, para así concluir señalando por qué la Corte Interamericana realizará una interpretación distinta a su homólogo europeo.

Palabras clave: Matrimonio, parejas del mismo sexo, homosexuales, Sistema Interamericano de Derechos Humanos, Corte Interamericana de Derechos Humanos.

\section{Same-sex marriage in the Inter-American System of Human Rights}

\begin{abstract}
The debate on same-sex marriage also exists within the international human rights systems. Since the Inter-American System of Human Rights has not settled a position on same-sex marriage yet, this article has as its main objective to predict which will be the decision of the Inter-American Court of Human Rights when it comes face to face with the matter. To do so, some relevant generalities of the Inter-American System of Human Rights and hermeneutic techniques used by the Inter-American Court are explained. In addition, a case from the European Court of Human Rights is analyzed, since in this case it was determined that the right to marriage only exists for different-sex couples. Finally, the article concludes explaining why the Inter-American Court of Human Rights will carry out a different interpretation of the right to marriage. Keywords: Marriage, same-sex couples, homosexuals, Inter-American System of Human Rights, Inter-American Court of Human Rights.
\end{abstract}

\section{A união de casais do mesmo sexo no Sistema Interamericano de Direitos Humanos}

\section{Resumo}

O debate sobre o direito à união de casais do mesmo sexo ocorre também no marco dos sistemas internacionais de direitos humanos. Devido a que dentro do Sistema Interamericano de Direitos Humanos ainda não existe uma postura ao respeito, este artigo tem como propósito anteceder qual poderia ser a decisão da Corte Interamericana de Direitos Humanos ao enfrentar-se o tema. Para isso, serão explicadas generalidades relevantes sobre o Sistema Interamericano e algumas técnicas interpretativas que a Corte Interamericana tem o costume de usar ao fixar o alcance dos direitos convencionais. Além disso, será feita uma referência a um caso em que o Tribunal Europeu de Direitos Humanos restringiu o direito à união só para casais heterossexuais, para assim concluir evidenciando por que a Corte Interamericana realizará uma interpretação distinta a seu homólogo europeu.

Palavras-chave: União, casais do mesmo sexo, homossexuais, Sistema Interamericano de Direitos Humanos, Corte Interamericana de Direitos Humanos. 


\section{Sumario}

Introducción - I. EL SISTEMA INTERAMERICANO DE DERECHOS HUMANOS - II. EL DERECHO AL MATRIMONIO EN EL SISTEMA INTERAMERICANO DE DERECHOS HUMANOS - III. EL CORPUS IURIS DE DERECHOS HUMANOS - IV. PERSPECTIVA DEL TRIBUNAL EUROPEO DE DERECHOS HUMANOS: EL CASO SCHALK \& KOPF VS. AUSTRIA - A. Los hechos del caso - B. Consideraciones sobre el derecho al matrimonio - C. Consideraciones sobre el derecho a la igualdad y no discriminación - D. La interpretación realizada por el Tribunal Europeo de Derechos Humanos - V. LAS FORMAS DE INTERPRETACIÓN DEL ARTÍCULO 17.2 DE LA CONVENCIÓN AMERICANA DE DERECHOS HUMANOS - A. Consideraciones generales sobre las pautas de interpretación de la Convención Americana de Derechos Humanos - B. Interpretación literal, sistemática y teleológica - C. Interpretación evolutiva vs. margen nacional de apreciación - D. Interpretación acorde al principio pro homine - E. Igualdad y no discriminación como norma ius cogens - VI. CONCLUSIONES - Bibliografía. 


\title{
El matrimonio de parejas del mismo sexo en el Sistema Interamericano de Derechos Humanos ${ }^{1}$
}

\author{
María Cecilia Ibáñez García
}

Introducción

Las personas lesbianas, gay, bisexuales, transexuales e intersexuales (en adelante LGBTI) han sido históricamente discriminadas en razón de su orientación sexual o identidad de género. Según el Informe anual del Alto Comisionado de las Naciones Unidas para los Derechos Humanos, del 17 de noviembre de 2011, la discriminación por estos motivos ocurre en todas las regiones, y se vislumbra en el empleo, la salud y la educación.

Adicionalmente, el informe muestra que la discriminación se manifiesta también mediante actos de violencia: asesinatos, violaciones y agresiones físicas, torturas, detenciones arbitrarias,

\footnotetext{
Cómo citar este artículo: Ibáñez García, M. C. (Junio, 2014). El matrimonio de parejas del mismo sexo en el Sistema Interamericano de Derechos Humanos. Revista de Derecho Público, 32.

2 Abogada de la Universidad de los Andes. A la fecha trabaja como abogada asistente del Doctor Manuel José Cepeda Espinosa. Correo: mc.ibanez25@uniandes.edu.co
}

y denegación de los derechos de reunión, expresión e información. El fundamento de estas afirmaciones son distintas encuestas e informes, tales como las siguientes:

\begin{abstract}
En un informe reciente del Consejo de Europa se constató que en todos sus Estados miembros había violencia y delitos motivados por el odio contra personas lesbianas, gays, bisexuales y trans. Según una encuesta llevada a cabo en 2008 en el Reino Unido por la ONG Stonewall (...) una tercera parte de las lesbianas y una cuarta parte de los gays habían sido víctimas de algún delito o incidente motivado por el odio (incluidas las agresiones verbales) en los tres años anteriores. En un estudio esloveno, el $53 \%$ de las personas lesbianas y gays encuestadas dijeron que habían sido víctimas de violencia en el pasado debido a su orientación sexual. (Organización de Naciones Unidas [onu], noviembre 17 de 2011, p. 9).
\end{abstract}

Ahora bien, la discriminación contra la población LGBTI se refleja también en el derecho. Un ejemplo claro de ello, y que existe hoy en día en la mayoría de los Estados del mundo, es la 
imposibilidad que tienen las parejas del mismo sexo - también denominadas parejas homosexuales- de contraer matrimonio.

Como consecuencia de movilizaciones sociales y de intervenciones jurídicas en favor de la igualdad de derechos entre parejas heterosexuales y homosexuales, en varios Estados ${ }^{3}$ se han ampliado instituciones de carácter civil, tales como la "unión de hecho" o "unión civil", para legalizar relaciones sentimentales entre parejas homosexuales. Además, con el tiempo se ha logrado también, en varios lugares, que las personas que conforman una unión de hecho tengan los mismos derechos que derivan del matrimonio, en materia de salud o pensiones, entre otros.

Aun así, la población LGBTI y sus aliados continúan luchando, tanto social como jurídicamente, para lograr que dentro de los Estados se legalice también el matrimonio entre parejas del mismo sexo. Los motivos concretos varían de Estado a Estado, pero debe tenerse en cuenta que estos no son necesariamente la obtención de mayores derechos o beneficios, pues como se señaló, en varios Estados las uniones de hecho cuentan con los mismos derechos que el matrimonio. La principal razón por la que se insiste tanto en la legalización del matrimonio de parejas homosexuales ha tomado un matiz de carácter simbólico, ya que aunque existen otras vías para que las parejas del mismo sexo legalicen sus uniones, y esta legalización les garantiza prácticamente los mismos derechos, sigue Tales como: Alemania, Austria, Colombia, Ecuador, Hungría, Finlandia, entre otros. habiendo un trato diferenciado: no pueden contraer matrimonio.

No obstante, a medida que pasan los años, cada vez más Estados avalan la posibilidad que parejas compuestas por dos personas del mismo sexo puedan legalizar su unión por medio de la institución del matrimonio.

El primer Estado que aprobó el matrimonio de parejas del mismo sexo fue los Países Bajos, desde el 1 de abril de 2001. A partir de entonces, entre los años 2003 y 2012 otros Estados europeos como Bélgica, España, Portugal, Noruega, Suecia, Islandia y Dinamarca otorgaron también a las parejas del mismo sexo la posibilidad de casarse.

En el continente americano, Canadá legalizó el matrimonio homosexual en el 2005, seguido por Argentina en el 2010. Sin embargo, en realidad el primer lugar de América en donde esto ocurrió no fue en un país, sino en el estado de Massachusetts de Estados Unidos, en el 2004. Siguiendo su ejemplo, siete estados estadounidense ${ }^{4}$ más legalizaron el matrimonio de parejas del mismo sexo entre 2008 y 2012. Asimismo, dos estados mexicanos, el Distrito Federal desde el 2010 y Quintana Roo desde 2011, también han legalizado el matrimonio de parejas homosexuales.

Podría decirse que el 2013 ha sido el año en que más avance ha habido en esta materia a ni-

4 Connecticut (2008), lowa (2009), Vermont (2009), Nuevo Hampshire (2010), Washington, D. C. (2010), Nueva York (2011), Washington (2012). 
vel mundial. En solo este año, Uruguay, Francia, Nueva Zelanda y Brasil, la capital australiana y siete estados estadounidenses más, reformaron su ordenamiento jurídico para permitir a las parejas del mismo sexo contraer matrimonio. Asimismo, dos de los países constituyentes del Reino Unido, Inglaterra y Gales, avalaron la posibilidad también en el 2013, ordenando que esta entre en vigencia en el 2014.

Como se puede observar, a medida que pasan los años, en más lugares del mundo se procede a reconocer a las parejas del mismo sexo la posibilidad de contraer matrimonio. Esto sin duda alguna es un avance en materia de derechos de la población LGBTI, principalmente porque ello representa una verdadera igualdad. Sin embargo, aún hay Estados en que el tema está lejos de ser pacífico, y continúa habiendo polémica en cuanto a si este paso debe tomarse o no.

Las controversias sobre permitir estas uniones suelen girar en torno a distintos tipos de argumentos. El principal se refiere al nivel de aceptación de estas uniones por parte de la población de un Estado específico, debido a que muchas personas las rechazan por razones religiosas, biológicas o morales. A esto se suman razones de carácter jurídico, tales como la redacción literal de las normas que se refieren al matrimonio y a la familia, la intención de quienes redactaron las normas relevantes o el alcance de los derechos fundamentales de los individuos.

Este tipo de debates, si bien surgen dentro de cada uno de los Estados, no son ajenos al sistema internacional. Esto, principalmente porque el derecho al matrimonio se encuentra consignado en distintos instrumentos internacionales de derechos humanos ${ }^{5}$. Este es el caso, por ejemplo, de la Convención Americana de Derechos Humanos $^{6}$, la cual consagra el derecho al matrimonio en el numeral segundo del artículo 17.

A la fecha no ha habido ningún pronunciamiento por parte de los órganos del Sistema Interamericano de Derechos Humanos ${ }^{7}$ que se refiera específicamente al derecho al matrimonio de parejas del mismo sexo. Sin embargo, teniendo en cuenta la situación actual de varios de los Estados partes de la Convención Americana, es posible que muy pronto surja la necesidad de que los órganos del Sistema Interamericano sienten una posición al respecto. De hecho, ya se han interpuesto dos peticiones individuales ante la Comisión Interamericana contra los Estados de Costa Rica y Chile, en que se alega la vulneración de distintos derechos debido a que los Estados no permiten el matrimonio de parejas del mismo sexo.

Lo preocupante para aquellos que defienden el derecho al matrimonio de parejas del mismo sexo no es solo la redacción literal del artículo 17.2 de la Convención Americana, el cual a primera vista parece consagrar el derecho al matrimonio únicamente para parejas hetero-

$5 \quad$ Ver por ejemplo: Asamblea General de las Naciones Unidas. Declaración Universal de Derechos Humanos. Diciembre 10 de 1948, artículo 16, y Convenio Europeo para la Protección de los Derechos Humanos y las Libertades Fundamentales, adoptado por el Consejo de Europa el 4 de noviembre de 1950, artículo 12.

6 En adelante "la Convención Americana" o "la Convención".

$7 \quad$ En adelante "el Sistema Interamericano". 
sexuales. Es inquietante también que, aunque no es del Sistema Interamericano, sí existe un pronunciamiento sobre el derecho al matrimonio de parejas del mismo sexo por parte de otro tribunal internacional, el Tribunal Europeo de Derechos Humanos, ${ }^{8}$ el cual realizó una interpretación restrictiva de este derecho al afirmar que efectivamente este se predica únicamente para parejas heterosexuales.

El Tribunal Europeo se pronunció al respecto en el caso Schalk \& Kopf vs. Austria en el año 2010, relativo a dos ciudadanos austriacos del mismo sexo que querían contraer matrimonio, y cuya solicitud fue negada por distintas autoridades de su país. En este caso, el Tribunal concluyó, entre otras cosas, lo siguiente: en primer lugar, que del Convenio Europeo de Derechos Humanos $^{9}$ no se desprende que los Estados tengan la obligación de permitir el matrimonio de parejas del mismo sexo, por lo que no se había configurado en aquel caso una vulneración del derecho al matrimonio; en segundo lugar y por la misma razón, que tampoco constituía una discriminación el no permitir el matrimonio entre parejas del mismo sexo. Todo lo anterior, lo determina el Tribunal con base en una interpretación literal, sistemática y teleológica de la norma, junto con el uso de una herramienta interpretativa conocida como la doctrina del margen nacional de apreciación.

Ahora bien, la interpretación que han hecho los órganos del Sistema Interamericano del derecho

8 En adelante "el Tribunal Europeo" o "el Tribunal".

9 En adelante "el Convenio Europeo" o "el Convenio". al matrimonio no es suficiente para determinar los alcances de este derecho y si este se predica tanto para parejas heterosexuales como homosexuales. Sumado a esto, la Corte Interamericana constantemente se nutre de la jurisprudencia del Tribunal Europeo de Derechos Humanos. Incluso, la forma en que ha ampliado y reconocido los derechos de las parejas del mismo sexo dentro de su jurisprudencia ha sido refiriéndose específicamente a casos de este Tribunal (Corte IDH, Atala Riffo y niñas vs. Chile, 2012).

Por ende, a primera vista es razonable esperar o prever que cuando la Corte Interamericana conozca de una pretensión en la que se alega la vulneración de los derechos al matrimonio y a la igualdad de parejas del mismo sexo, el precedente del Tribunal Europeo incidirá de forma significativa, dado que en el pasado ha usado su jurisprudencia como parámetro interpretativo. Además, existen similitudes dentro de los sistemas europeo y americano, tales como la redacción del artículo que consagra el derecho al matrimonio en los tratados respectivos, que justifican que la Corte realice la misma interpretación literal, sistemática y teleológica que su homólogo europeo.

Con todo, debe tenerse en cuenta que entre los dos sistemas también existen diferencias importantes. En todo caso, sea cual sea la decisión de la Corte Interamericana, esta será realmente significativa para la población LGBTI, ya que fijará la dirección que deben seguir los Estados partes de la Convención Americana frente a la materia. De esta forma, la pregunta que se pretende responder en el presente escrito es si la Corte Inte- 
ramericana, al enfrentarse a una pretensión relacionada con el matrimonio de parejas del mismo sexo, realizará la misma interpretación del derecho al matrimonio que el Tribunal Europeo.

Con base en lo anterior, este artículo tiene cinco capítulos principales y uno final de conclusiones. En el primer capítulo se hará una breve explicación de cómo funciona el Sistema Interamericano de Derechos Humanos, para ilustrar la manera en que una controversia como el matrimonio de parejas del mismo sexo puede llegar a ser evaluada dentro de este, así como la importancia de dicha decisión.

Luego, en el segundo capítulo se mostrará cómo está concebido el derecho al matrimonio dentro del Sistema Interamericano, y el desarrollo que este ha tenido dentro de las decisiones de la Corte mediante sus funciones contenciosa y consultiva.

Como consecuencia de lo anterior, en el tercer capítulo se hará una explicación de la herramienta interpretativa denominada corpus iuris de derechos humanos, en virtud de la cual la Corte Interamericana suele tener en cuenta distintos elementos del derecho internacional de derechos humanos, con el fin de interpretar las normas de la Convención Americana.

Posteriormente, y teniendo en cuenta los capítulos anteriores, en el cuarto capítulo se analizará el caso Schalk \& Kopf vs. Austria del Tribunal Europeo de Derechos Humanos, el cual es pertinente debido a que se trata de un caso en que un tribunal internacional se pronunció especí- ficamente sobre el derecho al matrimonio de las parejas del mismo sexo. Adicionalmente, se explicarán las herramientas de interpretación en las que se basó el Tribunal para llegar a sus conclusiones.

Luego, en el quinto capítulo se mostrará que la interpretación literal, sistemática y teleológica que realizó el Tribunal Europeo en el caso SchaIk y Kopf del derecho al matrimonio, es igualmente predicable del artículo 17.2 de la Convención Americana. Sin embargo, también se explicarán tres razones específicas por las cuales es altamente probable que la Corte Interamericana realice una interpretación diferente. Por último, en el sexto capítulo se esbozarán las conclusiones del escrito y se responderá a la pregunta concreta planteada anteriormente.

\section{EL SISTEMA INTERAMERICANO DE DERECHOS HUMANOS}

El Sistema Interamericano de Derechos Humanos es un sistema regional de promoción y protección de los derechos humanos. Sus dos órganos principales son la Comisión Interamericana de Derechos Humanos ${ }^{10}$ y la Corte Interamericana de Derechos Humanos. ${ }^{11}$

Adicionalmente, el instrumento normativo principal de este sistema es la Convención Americana de Derechos Humanos, un tratado internacional vinculante para los Estados del continente que

\footnotetext{
10 En adelante "la Comisión" o "la Comisión Interamericana".

11 En adelante "la Corte" o "la Corte Interamericana".
} 
la ratifiquen. En ella se encuentran consignados derechos humanos de los que son titulares los ciudadanos, así como obligaciones específicas que tienen los Estados para lograr el respeto y la garantía de estos derechos.

De esta forma, mediante el cumplimiento de ciertos requisitos de admisibilidad ${ }^{12} y$ competencia, ${ }^{13}$ ciudadanos que consideren que un Estado parte de la Convención Americana ha violado sus derechos humanos, pueden interponer una petición individual ante el Sistema. El procedimiento para este trámite se encuentra establecido tanto en la Convención Americana ${ }^{14}$ como en los reglamentos de la Comisión ${ }^{15} \mathrm{y}$ de la Corte..$^{16}$

En términos generales, el procedimiento es el siguiente: la Comisión debe admitir el caso y luego, mediante un informe de fondo, determinar si un Estado ha violado o no los derechos humanos alegados. En caso que la Comisión establezca que efectivamente ha habido una violación de derechos humanos por parte del Estado, se formulan recomendaciones al mismo, y se concede un plazo para cumplirlas. Si luego de finalizado el plazo el Estado no ha cumplido las recomendaciones, el Estado mismo o la Comisión están habilitados para remitir el caso a la Corte

12 Convención Americana de Derechos Humanos. Artículos 46 y 47.

13 Convención Americana de Derechos Humanos. Artículo 44.

14 Convención Americana de Derechos Humanos. Artículos 44 a 51.

15 Reglamento de la Comisión Interamericana de Derechos Humanos. Artículos 26-43.

16

Reglamento de la Corte Interamericana de Derechos Humanos.
Interamericana, la cual se pronunciará sobre los elementos de admisibilidad y de fondo de este.

Es mediante las decisiones de estos casos, denominados casos contenciosos, que la Corte Interamericana no solo se pronuncia en última instancia sobre la existencia o no de responsabilidad internacional de un Estado por violaciones de derechos humanos, sino que además fija el alcance y la interpretación de los derechos de la Convención.

Ahora bien, la Corte también tiene la posibilidad de interpretar y fijar el alcance de los derechos convencionales mediante opiniones consultivas. Estas resoluciones las expide como respuesta a inquietudes específicas de los Estados partes o de la Comisión Interamericana, sobre los derechos y las obligaciones convencionales.

Así las cosas, en tanto ya se han interpuesto dos peticiones individuales ante la Comisión, relacionadas con el matrimonio de parejas del mismo sexo, el trámite explicado se está surtiendo actualmente. Consecuentemente, pronto habrá un pronunciamiento de la Corte Interamericana sobre la materia mediante la resolución de un caso contencioso. También puede suceder, sin embargo, que un Estado parte o la misma Comisión solicite a la Corte que, mediante una opinión consultiva, se pronuncie sobre el alcance del derecho al matrimonio.

En cualquier caso, será necesario que al enfrentarse a esta materia la Corte Interamericana interprete el derecho al matrimonio y fije su alcance. Independientemente de cual sea la decisión, 
esta será de suma relevancia para los Estados partes de la Convención, pues determinará la dirección que deben seguir estos en cuanto al matrimonio de parejas homosexuales. Esto, no solo porque las decisiones de la Corte Interamericana constituyen precedente vinculante para Ios Estados (Hitters, 2013, p. 115), sino porque la interpretación que esta hace de los derechos convencionales, ya sea amplia o restrictiva, es la interpretación que se debe entender está plasmada en la Convención Americana de Derechos Humanos. Por ende, si un Estado específico ha ratificado esta Convención, debe aplicar lo que la Corte diga sobre ella.

\section{EL DERECHO AL MATRIMONIO EN EL SISTEMA INTERAMERICANO DE DERECHOS HUMANOS}

Es importante comenzar señalando cómo está consignado el derecho al matrimonio en la Convención Americana, y cuál ha sido el alcance que se le ha dado mediante las decisiones de la Corte. El derecho al matrimonio está consagrado en el artículo 17 de la Convención Americana de la siguiente forma:

\section{Artículo 17. Protección a la Familia}

1. La familia es el elemento natural y fundamental de la sociedad y debe ser protegida por la sociedad y el Estado.

2. Se reconoce el derecho del hombre y la mujer a contraer matrimonio $v$ a fundar una familia si tienen la edad v las condiciones requeridas para ello por las leves internas, en la medida en que éstas no afecten al principio de no discriminación establecido en esta Convención.

3. El matrimonio no puede celebrarse sin el libre y pleno consentimiento de los contrayentes. (...). [Negrillas y subrayas añadidas].

De la lectura del artículo 17 se desprende que el numeral primero define la "familia" y contiene la protección que el Estado y la sociedad deben otorgarle, mientras que el numeral segundo contiene explícitamente dos derechos distintos: el derecho al matrimonio y el derecho a fundar una familia.

Por su parte, los numerales 3, 4 y 5 se refieren a características específicas del matrimonio, a saber: el consentimiento de los contrayentes, la igualdad de derechos y equivalencia de responsabilidades de los cónyuges, y la igualdad de derechos para los hijos nacidos tanto fuera como dentro del matrimonio.

Ahora bien, además de lo dispuesto literalmente por el artículo 17, es pertinente traer a colación lo que la Corte Interamericana, mediante casos contenciosos u opiniones consultivas, ha dispuesto sobre el alcance y contenido de estas normas. Esto es importante para determinar si el derecho al matrimonio como tal y sus demás elementos son aplicables por igual a parejas de diferente sexo y a aquellas del mismo sexo.

De manera preliminar, sin embargo, debe advertirse que la Corte Interamericana nunca se ha referido al derecho al matrimonio establecido en el numeral segundo del artículo $17 \mathrm{y}$, en general, que son muy pocas las considera- 
ciones que se han realizado sobre el término "matrimonio".

En la Opinión Consultiva n. ${ }^{\circ} 4$, el Estado de Costa Rica solicitó el pronunciamiento de la Corte Interamericana sobre algunas reformas que pretendía realizar a su Constitución Política. Dentro del análisis realizado por la Corte se tuvo en cuenta el numeral 4 del artículo 17, sobre la igualdad de derechos y equivalencia de responsabilidades de los cónyuges dentro del matrimonio. Al respecto, la Corte encontró que algunas de las propuestas que incluía el proyecto de reforma costarricense eran discriminatorias, pues creaban condiciones preferentes para solo uno de los cónyuges en determinados casos (Corte IDH, OC-4/87, 1984.

En la Opinión Consultiva n. ${ }^{\circ} 17$, sobre la condición jurídica y los derechos humanos del niño, la Corte realizó algunas consideraciones breves sobre la familia y el matrimonio de la siguiente forma:

Es importante considerar el alcance que tiene el concepto de familia para radicar los deberes y facultades a los que hacemos referencia. La Corte Europea de Derechos Humanos ha sostenido en diversas ocasiones que el concepto de vida familiar 'no está reducid[o] únicamente al matrimonio y debe abarcar otros lazos familiares de hecho donde las partes tienen vida en común por fuera del matrimonio' (párr. 69).

De manera similar, en el caso Atala Riffo y niñas vs. Chile (2012), el cual se explicará en mayor detalle en las secciones posteriores, se hizo una consideración similar al concluir que el matrimonio no es la única forma de familia que debe ser protegida por el Estado y la sociedad en virtud del artículo 17.1 de la Convención. Así se pronunció la Corte en este caso:

La Corte constata que en la Convención Americana no se encuentra determinado un concepto cerrado de familia, ni mucho menos se protege sólo un modelo 'tradicional' de la misma. Al respecto, el Tribunal reitera que el concepto de vida familiar no está reducido únicamente al matrimonio y debe abarcar otros lazos familiares de hecho donde las partes tienen vida en común por fuera del matrimonio (párr. 142).

Ahora bien, es cierto que tanto la Opinión Consultiva n. ${ }^{\circ} 17$ como el caso Atala se refirieron a la noción de familia y establecieron explícitamente que el matrimonio no es la única manera en que esta se conforma. Sin embargo, esto no fue una interpretación de los alcances del derecho al matrimonio como tal, sino del concepto de familia.

Por último, recientemente el caso Artavia Murillo y otros vs. Costa Rica (2012) involucró un análisis relacionado con el derecho de los ciudadanos a fundar familias, en tanto el tema principal de este es la fecundación in vitro. Por ende, la Corte hace referencia a la protección de la que es titular la familia en virtud del artículo 17.1 de la Convención y, además, se menciona el numeral segundo del mismo artículo. No obstante, si bien el numeral segundo contiene el derecho al matrimonio, también contiene el derecho a "fundar una familia". Así las cosas, en tanto este último era el derecho pertinente para el caso, la Corte se refiere únicamente al 
derecho a fundar una familia cuando menciona el numeral 2 del artículo 17:

La Corte ya ha indicado que el derecho de protección a la familia conlleva, entre otras obligaciones, a favorecer, de la manera más amplia, el desarrollo y la fortaleza del núcleo familiar. (...) El artículo 17.2 de la Convención Americana protege el derecho a fundar una familia, el cual está ampliamente consagrado en diversos instrumentos internacionales de derechos humanos (párr. 145).

De lo descrito anteriormente se desprende que del artículo 17 y las interpretaciones que la Corte Interamericana ha hecho de este, es muy difícil extraer concretamente cuál es la postura del Sistema Interamericano en cuanto al derecho al matrimonio de las parejas del mismo sexo. Por ende, en el momento en que la Corte deba pronunciarse respecto a una pretensión sobre este tema específico, es muy probable que haga uso de otros conceptos, elementos y técnicas interpretativas para tomar una decisión.

Así las cosas, es pertinente hacer referencia a otros elementos del marco jurídico internacional que pueden ser utilizados por la Corte cuando llegue el momento de pronunciarse sobre el tema específico ya reiterado. El elemento concreto pertinente es el caso Schalk \& Kopf vs. Austria (2010) del Tribunal Europeo de Derechos Humanos, en el que este Tribunal se refirió específicamente al matrimonio de parejas del mismo sexo.

Ahora, si bien se trata de una sentencia de un tribunal que no es la Corte Interamericana, esto no es un impedimento para que lo dispuesto en ella pueda ser tenido en cuenta. Lo anterior, en virtud del corpus iuris de derechos humanos.

\section{EL CORPUS IURIS DE DERECHOS HUMANOS}

La Corte Interamericana constantemente se nutre de la jurisprudencia del Tribunal Europeo de Derechos Humanos. Esta posibilidad de tener en cuenta decisiones de otros tribunales internacionales se ha puesto en práctica en virtud del denominado corpus iuris de derechos humanos. Según lo ha definido la Corte, el corpus iuris abarca desde tratados y convenios hasta resoluciones y declaraciones (Corte IDH, Cabrera García y Montiel Flores vs. México, 2006), que sirven para fijar el contenido y los alcances de las normas de la Convención Americana (Corte IDH, OC-17/02, 2002). En otras palabras, se trata de una herramienta interpretativa que permite a la Corte Interamericana utilizar decisiones de otros órganos de derechos humanos para interpretar la Convención.

Esto ha sido realizado por la Corte en varias ocasiones. ${ }^{17}$ Una de las primeras veces fue en el caso Villagrán Morales y otros vs. Guatemala (1999), en el que se dispuso que:

Tanto la Convención Americana como la Convención sobre los Derechos del Niño forman parte de un muy comprensivo corpus juris

17 Ver por ejemplo: CORTE IDH. Caso Contreras y otros vs. El Salvador. (Fondo, Reparaciones y Costas). Sentencia de 31 de agosto de 2011. Serie C n. ${ }^{\circ}$ 232, párr. 112. Corte IDH. Caso Gelman vs. Paraguay (Fondo y Reparaciones), Sentencia de 24 de febrero de 2011. 
internacional de protección de los niños que debe servir a esta Corte para fijar el contenido y los alcances de la disposición general definida en el artículo 19 de la Convención Americana (párr. 194).

Más importante aún, el caso Atala Riffo y niñas vs. Chile (2012) es una muestra clara de por qué será necesario que la Corte Interamericana tenga en cuenta el caso Schalk y Kopf vs. Austria (2010) al pronunciarse sobre el matrimonio de parejas del mismo sexo. El caso Atala trata, en términos generales, sobre una mujer que es discriminada por distintas autoridades chilenas, las cuales le retiran la custodia de sus hijas bajo el argumento que, por su orientación sexual, no podía ejercer adecuadamente su rol de madre.

Este es el único caso de la Corte Interamericana en que se han evaluado los derechos de las personas homosexuales, y en que se han esbozado consideraciones relacionadas con la discriminación por orientación sexual. En este caso, la mayoría de los puntos novedosos relativos a parejas del mismo sexo fueron introducidos en el Sistema Interamericano teniendo en cuenta varios tratados internacionales y decisiones de otros órganos de derechos humanos.

Uno de los principales puntos novedosos del caso Atala fue la determinación acerca de que la orientación sexual es una de las categorías por las cuales está prohibido discriminar, según el artículo $1.1^{18}$ de la Convención Americana,

18 "Artículo 1. Obligación de Respetar los Derechos. 1. Los Estados Partes en esta Convención se comprometen a respetar los derechos y libertades reconocidos en ella y a garantizar su libre y pleno ejercicio a toda persona que esté sujeta a su jurisdicción, sin discrimi- incluso aunque esta no esté establecida en la norma de manera explícita.

Para llegar a la anterior conclusión, la Corte se remitió a pronunciamientos del Comité de Derechos Humanos y del Comité de Derechos Económicos, Sociales y Culturales, los cuales forman parte del Sistema Universal de Protección de Derechos Humanos, y han caracterizado la orientación sexual como una de las categorías por las que está prohibido discriminar. Adicionalmente, sobre esta misma materia, tuvo en cuenta la Corte lo dispuesto por el Tribunal Europeo de Derechos Humanos (TEDH. Caso Salgueiro da Silva Mouta vs. Portugal, 1999), el cual se enfrentó a una situación similar en relación con el artículo 14 del Convenio Europeo de Derechos Humanos, y concluyó que la orientación sexual era también una de las cláusulas protegidas por la prohibición de discriminación.

Asimismo, en el caso Atala se tuvieron en cuenta múltiples casos del Tribunal Europeo ${ }^{19}$ también para concluir otros aspectos. Algunos de ellos fueron: que la única manera de conformar una familia no es mediante el matrimonio, que el derecho a la vida privada consagrado en el artículo 11.2 de la Convención Americana prote-

nación alguna por motivos de raza, color, sexo, idioma, religión, opiniones políticas o de cualquier otra índole, origen nacional o social, posición económica, nacimiento o cualquier otra condición social".

Entre otros: TEDH. Caso Salgueiro da Silva Mouta vs. Portugal, (n. ${ }^{\circ}$ 33290/96), sentencia de 21 de diciembre de 1999; TEDH. Caso Pretty vs. Reino Unido, (n. $\left.{ }^{\circ} 2346 / 02\right)$, sentencia de 29 de abril de 2002 . Final, 29 de julio de 2002; TEDH. Caso Peck vs. Reino Unido, (n. ${ }^{\circ} 44647 / 98$ ), sentencia de 28 de enero de 2003. Final, 28 de abril de 200; TEDH, Karner vs. Austria, (n. ${ }^{\circ}$ 40016/98), sentencia de 24 de julio de 2003; TEDH. Caso E.B. vs, Francia, (n. $\left.{ }^{\circ} 43546 / 02\right)$, sentencia de 22 de enero de 2008; TEDH. Caso Clift vs. Reino Unido, (n. $\left.{ }^{\circ} 7205 / 07\right)$, sentencia de 13 de julio de 2010. Final, 22 de noviembre de 2010. 
ge el que una persona no solo sea homosexual sino que además pueda desarrollarse como tal, y que las uniones de personas del mismo sexo están protegidas de las injerencias arbitrarias o abusivas del Estado en la medida en que estas pueden llegar a conformar vida familiar (TEDH, Schalk y Kopf vs. Austria, 2010).

De esta forma, queda claro que es usual que la Corte en algunos casos, aún más en materia de orientación sexual, se remita a lo dispuesto por otros órganos de derechos humanos, entre ellos, el Tribunal Europeo.

Así, teniendo en cuenta que el derecho al matrimonio se ha desarrollado muy poco dentro de la jurisprudencia interamericana, y que en la jurisprudencia europea existe un caso específico sobre matrimonio de parejas del mismo sexo, a primera vista es razonable prever que este precedente juegue un papel importante en el momento en que la Corte Interamericana deba pronunciarse sobre la materia.

\section{PERSPECTIVA DEL TRIBUNAL EUROPEO DE DERECHOS HUMANOS: EL CASO SCHALK \& KOPF VS. AUSTRIA}

Como ya se ha mencionado, el caso Schalk \& Kopf vs. Austria del Tribunal Europeo de Derechos Humanos es relevante para el presente escrito porque es un caso en que un tribunal internacional se pronunció específicamente sobre el derecho al matrimonio de las parejas del mismo sexo. En la sentencia que resolvió la demanda, el Tribunal Europeo fijó el alcance del derecho al matrimonio y las obligaciones de los Estados partes del Convenio Europeo de Derechos Humanos frente al mismo.

A continuación se explica brevemente el caso, así como las consideraciones realizadas en cuanto al derecho al matrimonio. Esto, ya que algunas de las consideraciones serán relevantes para la Corte Interamericana, cuando Ilegue su momento de pronunciarse al respecto.

\section{A. Los hechos del caso}

Los demandantes son dos individuos, Schalk \& Kopf, una pareja del mismo sexo que vive en Viena, Austria. El 10 de septiembre de 2002, los demandantes iniciaron los trámites internos dentro del Estado austriaco para contraer matrimonio. Sin embargo, las distintas instancias a las que acudieron les negaron la solicitud, alegando que el artículo 44 del Código Civil establece que el matrimonio solo puede ser contraído por parejas heterosexuales.

Posteriormente, los demandantes acudieron ante el Tribunal Constitucional de Austria arguyendo que el no permitirles contraer matrimonio atentaba contra su derecho a la igualdad y no discriminación, entre otros. No obstante, este Tribunal concluyó lo mismo que las instancias anteriores, y negó la solicitud de Schalk y Kopf.

En consecuencia, los demandantes comparecieron ante el Sistema Europeo de Derechos Humanos alegando la violación de varios derechos consagrados en el Convenio Europeo: el derecho al matrimonio consagrado en el artícu- 
lo 12 , los derechos a la vida privada y familiar consignados en el artículo 8 en conjunción con el artículo 14 sobre la prohibición de discriminación, y el artículo 1 del Protocolo n. ${ }^{\circ} 1$ Adicional al Convenio, relacionado con la posibilidad de disfrutar de sus posesiones.

\section{B. Consideraciones sobre el derecho al matrimonio}

El artículo 12 del Convenio Europeo de Derechos Humanos consagra el derecho al matrimonio, y está redactado de la siguiente forma:

“Artículo 12. Derecho a contraer matrimonio. A partir de la edad núbil, el hombre y la mujer tienen derecho a casarse y a fundar una familia según las leyes nacionales que rijan el ejercicio de este derecho".

La pretensión de los demandantes en cuanto a este derecho consistía, básicamente, en que de la lectura de la norma no se desprende necesariamente que el derecho al matrimonio estuviese contemplado únicamente para parejas heterosexuales. Así, al no permitirle a una pareja homosexual contraer matrimonio, un Estado incurría en responsabilidad internacional por violación del artículo 12.

Al respecto, las consideraciones del Tribunal fueron las siguientes. En primer lugar, señaló que esta era la primera vez que se enfrentaba a una situación sobre el derecho al matrimonio de parejas del mismo sexo. En casos anteriores como Christine Goodwin vs. Reino Unido, el Tribunal estudió un caso de una persona transgénero que deseaba contraer matrimonio con una persona del sexo opuesto a su género adquirido. Al respecto, concluyó que los criterios de "hombre y mujer" contenidos en el artículo 12 del Convenio Europeo no debían entenderse únicamente en el sentido biológico, dado que la institución del matrimonio ha cambiado con el tiempo.

Sin embargo, luego el Tribunal se refiere a dos casos similares: Parry vs. Reino Unido y R. \& F. vs. Reino Unido, los cuales involucraban a una pareja casada conformada por una mujer y una mujer transgénero. Ambas parejas alegaban que si uno de los cónyuges deseaba obtener reconocimiento legal de su cambio de género, debían terminar su matrimonio. Frente a esto, el Tribunal señaló que la ley en el Reino Unido solo permitía el matrimonio entre dos personas de género opuesto, así dicho género derivara de una condición biológica o de un proceso posterior de cambio de género, mientras que matrimonios entre personas del mismo sexo no estaban permitidos. De forma similar, estableció el Tribunal, el artículo 12 del Convenio Europeo contiene el concepto tradicional de matrimonio: entre un hombre y una mujer (TEDH, Schalk y Kopf vs. Austria, párr. 53). Por ende, no encontró fundada la petición de los demandantes.

Luego de hacer el recuento de la jurisprudencia pertinente, el Tribunal se enfoca en la redacción del artículo 12. Al respecto, estableció lo siguiente:

La Corte observa que, vista de manera aislada, la redacción del Artículo 12 puede ser interpretada en un sentido en que no excluye el 
matrimonio entre dos hombres o dos mujeres. Sin embargo, en contraste, todos los demás Artículos sustantivos de la Convención conceden derechos y libertades a "todos" o establecen que "nadie" debe ser sujeto de ciertos tipos de trato prohibidos. La escogencia de palabras del Artículo 12 debe entonces ser considerada intencional. Además, debe tenerse en cuenta el contexto histórico en que la Convención fue adoptada. En 1950 el matrimonio claramente era entendido en un sentido tradicional de unión de compañeros de distinto sexo (TEDH, Schalk \& Kopf vs. Austria, 2010).

Adicionalmente, el Tribunal se refiere a uno de los argumentos de los peticionarios frente a esta pretensión, el cual consiste en que el Convenio es un instrumento vivo que debe ser interpretado según las condiciones de vida actuales. Esta forma de interpretación que sugieren los peticionarios se denomina interpretación evolutiva, y en efecto ha sido utilizada por el Tribunal Europeo anteriormente. ${ }^{20}$ Sin embargo, el Tribunal sostiene que no ha sido persuadido por este argumento de los peticionarios (párr. 58).

Por el contrario, el Tribunal establece que no existe consenso entre los Estados partes del Convenio en cuanto a permitir el matrimonio de parejas del mismo sexo. Lo anterior pues, en el año 2010, únicamente 6 de los 47 Estados partes permitían el matrimonio de parejas del mismo sexo. Sumado a esto, el Tribunal también tiene en cuenta que

20 Ver por ejemplo: TEDH. Caso Tyrer v. Reino Unido, (n. ${ }^{\circ}$ 5856/72), sentencia de 25 de abril de 1978, párr. 31. el matrimonio tiene connotaciones sociales y culturales profundas que pueden diferir bastante entre una sociedad y otra. Reitera la Corte que no debe entonces sustituir su propio criterio en lugar del de las autoridades nacionales, las cuales están mejor ubicadas para evaluar y responder a las necesidades de la sociedad (párr. 62).

Así las cosas, se desprende de lo anterior que los motivos por los cuales el Tribunal se niega a hacer uso de la interpretación evolutiva sugerida por los peticionarios se debe a: primero, la falta de consenso entre los Estados de la región en cuanto a la materia, y segundo, la necesidad de tener en cuenta la mentalidad o características específicas de una sociedad en concreto.

Con base en todo lo anterior, encuentra el Tribunal que el artículo 12 del Convenio Europeo no impone a los Estados la obligación de reconocer el matrimonio de parejas del mismo sexo. Consecuentemente, se considera que no hubo en este caso una violación del derecho al matrimonio (párr. 63).

\section{Consideraciones sobre el derecho a la igualdad y no discriminación}

Por otra parte, los peticionarios también alegaron la violación a su derecho a la igualdad y no discriminación, por dos motivos. Uno de ellos, el pertinente para este escrito, era precisamente el que no se les permitía contraer matrimonio.

Sin embargo, haciendo referencia a las consideraciones anteriormente esbozadas sobre por qué no había una vulneración del derecho 
al matrimonio de los demandantes, el Tribunal sostiene que, por esto, no existe tampoco una discriminación. Concretamente, así se pronunció el Tribunal:

el Convenio debe ser leído como un todo y sus Artículos deben, por consiguiente, ser interpretados en armonía los unos con los otros. Teniendo en cuenta la conclusión a la que se llegó arriba, específicamente que el Artículo 12 no impone la obligación a los Estados partes de garantizar a las parejas del mismo sexo el acceso al matrimonio, el artículo 14 en conjunción con el Artículo 8, una provisión de un propósito y ámbito más general, tampoco puede ser interpretada en el sentido que imponga esa obligación (párr. 101). ${ }^{21}$

De esta forma, en este caso el Tribunal Europeo de Derechos Humanos tampoco encontró que el no permitir que parejas del mismo sexo pudieran contraer matrimonio generara una vulneración del derecho a la igualdad y no discriminación.

\section{La interpretación realizada por el Tribunal Europeo de Derechos Humanos}

Con base en la descripción anterior, es posible concluir que para fijar el alcance del derecho al matrimonio según el Convenio Europeo de Derechos Humanos, el Tribunal Europeo se basó, primero, en una interpretación literal, sistemática y

21 Ibid. Párr. 101. "It reiterates that the Convention is to be read as a whole and its Articles should therefore be construed in harmony with one another (see Johnston and Others, cited above, § 57). Having regard to the conclusion reached above, namely that Article 12 does not impose an obligation on Contracting States to grant same-sex couples access to marriage, Article 14 taken in conjunction with Article 8, a provision of more general purpose and scope, cannot be interpreted as imposing such an obligation either". teleológica de la norma. Esto, en virtud de las reglas generales de interpretación de los tratados internacionales, establecidas en el artículo $31^{22}$ de la Convención de Viena sobre el Derecho de los Tratados.

De este artículo surge la posibilidad de interpretar de estas tres maneras, entre otras, en tanto establece que la interpretación debe ser "conforme al sentido corriente de los términos" - literal-, según el texto del tratado junto con su preámbulo y anexos - sistemática-, y “teniendo en cuenta su objeto y fin" -teleológica-.

La interpretación que realiza el Tribunal Europeo es literal y sistemática, pues a partir de las palabras contenidas en el artículo y su lectura en conjunto con el resto del Convenio Europeo, se concluye que las palabras "hombre" y "mujer" fueron elegidas intencionalmente, por lo que debía entenderse que el artículo 12 del Convenio consagra el derecho al matrimonio únicamente para parejas heterosexuales.

Aunado a lo anterior, la interpretación es también teleológica, pues el Tribunal tiene en cuenta la fecha en que se creó el Convenio Europeo para determinar cuál era la concepción del matrimonio en aquel entonces y, por ende, qué era lo que se había pretendido incluir en su texto. Así, debido a que el Convenio es de 1950 y en

22 “31. Regla general de interpretación. I. Un tratado deberá interpretarse de buena fe conforme al sentido corriente que haya de atribuirse a los términos del tratado en el contexto de estos y teniendo en cuenta su objeto y fin. 2. Para los efectos de la interpretación de un tratado. [sic] el contexto comprenderá, además del texto, incluidos su preámbulo y anexos: (...) 3. Juntamente con el contexto, habrá de tenerse en cuenta: (...) 4. Se dará a un término un sentido especial si consta que tal fue la intención de las partes". 
aquella época el matrimonio se concebía únicamente para parejas heterosexuales, concluye el Tribunal que la finalidad de la norma era justamente consagrar el matrimonio únicamente para este tipo de parejas.

Sin embargo, no hay que dejar de lado otra herramienta interpretativa que utiliza el Tribunal Europeo, además de las mencionadas en los párrafos anteriores. Como se señaló en la sección 4.2 de este escrito, los demandantes sugirieron al Tribunal que hiciera uso de una manera específica de interpretación. Concretamente, recordaron al Tribunal que este muchas veces ha reconocido que "los tratados internacionales de derechos humanos son instrumentos vivos que deben interpretarse de acuerdo a las condiciones de vida actuales." (TEDH, Tyrer vs. Reino Unido, 1978, párr. 31). ${ }^{23}$

No obstante, el Tribunal Europeo no acogió esta sugerencia de los peticionarios y, por el contrario, recurrió a dos elementos: primero, la falta de consenso regional en cuanto a otorgar a las parejas del mismo sexo la posibilidad de contraer matrimonio y, segundo, la concepción del matrimonio en la sociedad austriaca. Ahora bien, al continuar refiriéndose a estos dos elementos dentro de la sentencia, afirma el Tribunal que cuando el consenso regional no existe se debe permitir que los Estados cuenten con un margen de apreciación, con base en el cual ellos mismos pueden fijar el alcance de los derechos convencionales. He aquí la otra herra-

23 TEDH. Caso Tyrer vs. Reino Unido, (n. ${ }^{\circ}$ 5856/72), sentencia de 25 de abril de 1978, párr. 31; TEDH. Caso E.B. vs. Francia, (n. ${ }^{\circ} 43546 / 02$ ), sentencia de 22 de enero de 2008. mienta interpretativa que tuvo en cuenta el Tribunal Europeo.

La doctrina del "margen nacional de apreciación" tiene su fundamento en la relación inescindible que existe entre el derecho internacional de los derechos humanos y el derecho interno. Aunque las definiciones realizadas sobre lo que constituye esta doctrina varían de doctrinante a doctrinante, en términos generales se entiende que el margen de apreciación es "un criterio de interpretación y aplicación de los derechos humanos, atribuido al Estado por parte de los tribunales regionales" (Barbosa Delgado, 2012, p. 44).

La manera en que el Tribunal Europeo justifica el reconocimiento de esta forma de interpretación de los derechos humanos surge de dos motivos distintos, ambos tenidos en cuenta en el caso Schalk y Kopf. En algunos casos se reconoce el margen de apreciación en virtud del contexto social de un Estado, y, en otros, el elemento que se tiene en cuenta es la ausencia de consenso regional frente a un tema concreto.

Ahora bien, aunque la herramienta interpretativa como tal fue utilizada desde antes, la expresión “margen nacional de apreciación” no se materializó de manera literal sino hasta el año 1971. Esto tomó lugar en el caso De Wilde, Ooms et Versyp vs. Bélgica, en el que el Tribunal consideró que el Estado no había vulnerado el artículo 8.2 del Convenio, el cual protege el derecho a la vida privada, al detener a un grupo de vagabundos. Lo anterior, toda vez que el Tribunal consideró que el Estado pudo haber teni- 
do razones valederas para hacerlo con base en la moral, salud y reputación de otros (Barbosa Delgado, 2011). A partir de este punto, el Tribunal Europeo continuó haciendo uso del término en casos reconocidos como Handyside vs. Reino Unido (1976), hasta en otros más recientes como Karner vs. Austria (2003).

El concepto de margen nacional de apreciación es, entonces, otra técnica interpretativa utilizada por el Tribunal Europeo en algunas ocasiones. En este caso se evidencia su utilización, como ya fue mencionado, en tanto el Tribunal tiene en cuenta la falta de consenso regional sobre los derechos de las parejas del mismo sexo y el contexto social austriaco, como argumentos complementarios a la redacción del artículo 12.

En síntesis, las técnicas interpretativas utilizadas por el Tribunal Europeo para decidir sobre el matrimonio de parejas del mismo sexo fueron de carácter literal, sistemático, teleológico, y complementadas por los elementos que permiten conceder a los Estados un margen de apreciación: consenso regional y características sociales concretas.

\section{LAS FORMAS DE INTERPRETACIÓN DEL ARTÍCULO 17.2 DE LA CONVENCIÓN AMERICANA DE DERECHOS HUMANOS}

De lo explicado en las secciones anteriores es válido extraer las siguientes conclusiones preliminares. Primera, el derecho al matrimonio, consagrado en la Convención Americana, no plantea nada explícito en cuanto a parejas del mismo sexo. Segunda, de los pronunciamientos de la Corte Interamericana sobre el matrimonio no es posible dilucidar cuál es su posición en materia del matrimonio de parejas del mismo sexo. Por ende, y tercera, en el momento en que la Corte Interamericana deba pronunciarse al respecto, es necesario y razonable que construya una interpretación teniendo en cuenta otras decisiones del marco internacional sobre el tema.

Cuarta, en el caso Schalk \& Kopf vs. Austria el Tribunal Europeo analizó los alcances del derecho al matrimonio según el Convenio Europeo. Mediante una interpretación literal, sistemática y teleológica, junto con el uso de la doctrina del margen nacional de apreciación, concluyó el Tribunal que el derecho al matrimonio estaba consagrado únicamente para parejas de diferente sexo, y que el que un Estado no lo permitiera para parejas del mismo sexo no constituía una vulneración del derecho al matrimonio ni una discriminación.

Con todo, en este acápite se demostrará que, aunque la interpretación literal, sistemática y teleológica que realizó el Tribunal Europeo en el caso Schalk y Kopf es igualmente aplicable al artículo 17.2 de la Convención Americana, existen otros elementos que permiten concluir que la futura interpretación que realice la Corte Interamericana será distinta a la del Tribunal Europeo. Esto se debe a tres razones principales.

Primera, que la Corte Interamericana no ha utilizado la doctrina del margen nacional de 
apreciación al igual que el Tribunal Europeo y, por el contrario, sí ha acogido la técnica de la interpretación evolutiva, desechada por el Tribunal Europeo en el caso Schalk y Kopf. Segunda, que otra de las pautas interpretativas en que ha hecho énfasis la Corte Interamericana es aqueIla acorde con el principio pro homine, según el cual debe privilegiarse la interpretación que sea más favorable al ser humano. Tercera, que la igualdad y no discriminación dentro del Sistema Interamericano es una norma de carácter ius cogens, sumado a que la prohibición de discriminación está explícita dentro del artículo 17 de la Convención Americana.

\section{A. Consideraciones generales sobre las pautas de interpretación de la Convención Americana de Derechos Humanos}

Las pautas para interpretar la Convención Americana surgen, principalmente, de dos fuentes normativas. En primer lugar, en tanto el derecho internacional de los derechos humanos hace parte del derecho internacional público, por supuesto son relevantes las pautas interpretativas consagradas en los artículos 31 y 32 de la Convención de Viena sobre el Derecho de los Tratados, los cuales contienen las reglas generales de interpretación y los medios de interpretación complementarios de los tratados internacionales, respectivamente.

Por otra parte, es relevante también el artículo 29 de la Convención Americana, el cual consagra específicamente las pautas interpretativas específicas para este tratado. De esta forma, tanto el artículo $29^{24}$ como las pautas interpretativas del derecho internacional público en general, pueden ser tenidos en cuenta al interpretar la Convención Americana.

\section{B. Interpretación literal, sistemática y teleológica}

En el Convenio Europeo el derecho al matrimonio está consagrado de manera independiente en un solo artículo, mientras que en la Convención Americana el mismo está enmarcado dentro del artículo sobre protección a la familia. Sin embargo, ambas normas son muy similares.
24 “Artículo 29. Normas de Interpretación. Ninguna disposición de la presente Convención puede ser interpretada en el sentido de: a) permitir a alguno de los Estados Partes, grupo o persona, suprimir el goce y ejercicio de los derechos y libertades reconocidos en la Convención o limitarlos en mayor medida que la prevista en ella; b) limitar el goce y ejercicio de cualquier derecho o libertad que pueda estar reconocido de acuerdo con las leyes de cualquiera de los Estados Partes o de acuerdo con otra convención en que sea parte uno de dichos Estados; c) excluir otros derechos y garantías que son inherentes al ser humano o que se derivan de la forma democrática representativa de gobierno, y d) excluir o limitar el efecto que puedan producir la Declaración Americana de Derechos y Deberes del Hombre y otros actos internacionales de la misma naturaleza". 


\begin{tabular}{|c|c|}
\hline \multicolumn{2}{|c|}{ DERECHO AL MATRIMONIO } \\
\hline Convención Americana & Convenio Europeo \\
\hline $\begin{array}{l}\text { "Articulo 17. Protección a } \\
\text { la Familia. } \\
\text { (...) } \\
\text { 2. Se reconoce el derecho } \\
\text { del hombre y la mujer a } \\
\text { contraer matrimonio y a } \\
\text { fundaruna familia sitienen } \\
\text { la edad y las condiciones } \\
\text { requeridas para ello por } \\
\text { las leyes internas, en la } \\
\text { medida en que estas no } \\
\text { afecten al principio de no } \\
\text { discriminación establecido } \\
\text { en esta Convención. } \\
\text { (...)" }\end{array}$ & $\begin{array}{l}\text { "Artículo 12. Derecho a } \\
\text { contraer matrimonio. } \\
\text { A partir de la edad } \\
\text { núbil, el hombre y la } \\
\text { mujer tienen derecho a } \\
\text { casarse y a fundar una } \\
\text { familia según las leyes } \\
\text { nacionales que rijan el } \\
\text { ejercicio de este dere- } \\
\text { cho". }\end{array}$ \\
\hline
\end{tabular}

Teniendo en cuenta la similitud de las normas, es posible sostener que la interpretación literal, sistemática y teleológica que realizó el Tribunal Europeo del artículo 12 del Convenio Europeo es predicable también del artículo 17 de la Convención Americana.

En primer lugar, de la lectura literal y aislada del artículo 17.2 puede extraerse que está permitido por la Convención que existan matrimonios entre dos hombres y dos mujeres. Sin embargo, al leer la norma en armonía con los demás artículos de la Convención, es claro que esta tiene una particularidad importante. Al igual que lo dispuso el Tribunal Europeo en el caso Schalk y Kopf, los demás artículos convencionales se refieren a "personas" en general, o señalan que "nadie" puede ser sujeto de un trato específico. Consecuentemente, la interpretación literal y sistemática de la norma es la misma.

En segundo lugar, teniendo en cuenta que la Convención Americana es del año 1969, es posi- ble afirmar que la concepción de la época sobre el derecho al matrimonio consistía en que este era una institución para parejas heterosexuales, al igual que en el momento de creación del Convenio Europeo. De ahí que también aplica la interpretación teleológica de la norma.

Por consiguiente, es válido sostener que, al igual que el artículo 12 del Convenio Europeo, el uso de las palabras "hombre y mujer" del artículo 17.2 fue intencional. Así, a primera vista, de la Convención Americana no se desprende para los Estados partes la obligación de permitir el matrimonio de parejas del mismo sexo, por lo que si un Estado no lo hace, no está incurriendo en una violación del derecho al matrimonio y tampoco de la prohibición de discriminación.

La interpretación anterior es perfectamente aplicable, pero no es la única relevante.

\section{Interpretación evolutiva vs. margen nacional de apreciación}

Como se estableció en el acápite sobre el caso Schalk y Kopf, concretamente en la sección IV de este escrito, el Tribunal Europeo rechazó hacer uso de la denominada interpretación evolutiva y, por el contrario, aplicó los elementos que conforman la herramienta interpretativa del denominado margen nacional de apreciación: consenso regional y características sociales específicas.

Ahora bien, ambas técnicas han sido originalmente planteadas y desarrolladas por el Tribunal Europeo de Derechos Humanos. Sin embargo, 
solo una de ellas, la interpretación evolutiva, ha sido acogida de forma constante y reiterada por la Corte Interamericana, como se evidenciará más adelante. La doctrina del margen nacional de apreciación, por el contrario, no ha sido utilizada de la misma forma. Es más, el ahora juez de la Corte Internacional de Justicia y anterior presidente de la Corte Interamericana, Cançado Trindade, llegó a establecer de manera explícita que era una fortuna que la doctrina del margen de apreciación no hubiese encontrado un paralelo explícito en el Sistema Interamericano (Núñez Poblete, 2012, p. 12). Esto último, si bien no debe generalizarse, sí permite vislumbrar al menos someramente que los miembros de la Corte Interamericana han sido conscientemente renuentes a aplicar la doctrina del margen de apreciación igual que el Tribunal Europeo.

El número de veces que la Corte Interamericana se ha referido a la doctrina del margen nacional de apreciación es notoriamente reducido en comparación con el uso que le ha dado el Tribunal Europeo. Sumado a esto, las veces que la Corte efectivamente ha aplicado esta doctrina explícitamente además de solo referirse a ella, son casi nulas. ${ }^{25}$

Por ejemplo, en el caso Herrera Ulloa vs. Costa Rica (2004), al referirse a la obligación que

25 La excepción es la Opinión Consultiva OC-4/84. Propuesta de modificación a la Constitución Política de Costa Rica relacionada con la naturalización. 19 de enero de 1984. Serie A n. ${ }^{\circ}$ 04. Párr. 62. "Esa conclusión de la Corte tiene especialmente en cuenta el margen de apreciación reservado al Estado que otorga la nacionalización sobre los requisitos y conclusiones que deben llenarse para obtenerla. Pero de ningún modo podría verse en ella una aprobación a la tendencia existente en algunas partes a restringir exagerada e injustificadamente el ámbito de ejercicio de los derechos políticos de los naturalizados". tienen los Estados de garantizar el derecho de los ciudadanos a recurrir el fallo ante un tribunal superior, la Corte estableció lo siguiente:

161. De acuerdo al objeto y fin de la Convención Americana, cual es la eficaz protección de los derechos humanos, se debe entender que el recurso que contempla el artículo 8.2.h. de dicho tratado debe ser un recurso ordinario eficaz mediante el cual un juez o tribunal superior procure la corrección de decisiones jurisdiccionales contrarias al derecho. Si bien los Estados tienen un margen de apreciación para regular el ejercicio de ese recurso, no pueden establecer restricciones o requisitos que infrinjan la esencia misma del derecho de recurrir del falo. (Párr. 161). [Subrayas añadidas].

De forma similar, recientemente en el caso Artavia Murillo y otros vs. Costa Rica (2012), el Estado alegó que debía reconocerse el margen de apreciación con que cuentan los Estados para “otorgar la condición de niños a menores no nacidos" (párr. 169). Señaló el Estado también que no existe consenso regional en cuanto al estatus jurídico del embrión, cuando se entiende que comienza una vida humana, o en cuanto a la utilización de la técnica de la fecundación in vitro. Sin embargo, al respecto la Corte determinó de forma explícita que no evaluaría el argumento del Estado de Costa Rica sobre el margen de apreciación, simplemente porque consideró que ya era evidente la violación de ciertos derechos (párr. 316).

Doctrinantes como Manuel Núñez Poblete y Héctor Fáundez Ledesma sostienen que, aunque no de la misma forma que el Tribunal Europeo, la 
Corte Interamericana sí ha hecho uso sustancial de la doctrina del margen nacional de apreciación (Fáundez Ledesma, 2004, p. 57). No obstante, los ejemplos de los que hacen uso para demostrar la utilización de esta doctrina no son equiparables a la aplicación que de ella hace el Tribunal Europeo.

Núñez Poblete, por ejemplo, afirma que el uso del margen nacional de apreciación es evidente en casos como Castañeda Gutman vs. México (2008), en el que se analizaron los requisitos para poder ejercer derechos políticos. En este caso la Corte sostuvo que: "Siempre que no sean desproporcionados o irrazonables, se trata de límites que legítimamente los Estados pueden establecer para regular el ejercicio y goce de los derechos políticos y que se refieren a ciertos requisitos que las personas titulares de los derechos políticos deben cumplir para poder ejercerlos" (párr. 155).

Así mismo, este autor se refiere también al caso Chaparro Álvarez y Lapo Iñiguez vs. Ecuador (2007), en el que la Corte evaluó las condiciones materiales que justifican la aplicación de medidas cautelares, y al respecto concluyó: “EI Tribunal recalca que son las autoridades nacionales las encargadas de valorar la pertinencia o no del mantenimiento de las medidas cautelares que emiten conforme a su propio ordenamiento" (párr. 107).

Ahora bien, ciertamente en casos como los citados anteriormente y utilizados por Núñez Poblete para sustentar su tesis, la Corte reconoce situaciones en que corresponde a los Estados regular ciertas materias de manera independiente y según su ordenamiento jurídico. Esto es apenas lógico, en la medida en que los sistemas de derecho internacional son de carácter coadyuvante y complementario (Corte IDH, Velásquez Rodríguez vs. Honduras, 1988), lo que implica que no deben regular absolutamente todas las materias dentro de cada uno de los Estados.

Sin embargo, además de que el término margen nacional de apreciación no se utiliza de forma explícita en estos casos, el argumento anterior no es suficiente para sostener que esta doctrina se aplica al igual que el Tribunal Europeo.

Como se señaló en el acápite sobre el caso Schalk y Kopf, el Tribunal Europeo aplica el margen nacional de apreciación no solo frente a elementos particulares de cada uno de los derechos, como los requisitos para ejercer derechos políticos, sino sobre el alcance de los derechos en su totalidad, lo que no se evidencia en los ejemplos anteriores. Además, la aplicación de esta doctrina, según el Tribunal Europeo, cuenta con dos elementos, el consenso regional y las particularidades sociales de cada Estado, los cuales tampoco son mencionados en los ejemplos de Núñez Poblete.

Así las cosas, si bien en los casos Castañeda y Chaparro Álvarez de la Corte Interamericana se señala que en algunas circunstancias las autoridades estatales tienen la facultad de determinar ciertos elementos de los derechos, no por ello puede sostenerse que entonces la doctrina del margen nacional de apreciación del Tribu- 
nal Europeo se aplica de la misma forma en el Sistema Interamericano. Incluso, los elementos del consenso regional y de las particularidades sociales de cada Estado no han tenido cabida en la jurisprudencia de la Corte Interamericana.

Por ejemplo, en el caso Atala Riffo y niñas vs. Chile (2012), si bien no se habló específicamente sobre el margen de apreciación, la Corte rechazó explícitamente uno de sus elementos: las características específicas de la sociedad chilena en cuanto a la materia. Uno de los argumentos del Estado de Chile para defender las conductas discriminatorias en que incurrieron las autoridades judiciales internas, consistía en que no había un consenso al interior de este sobre los derechos de las minorías sexuales. A este argumento, la Corte Interamericana respondió lo siguiente:

la presunta falta de un consenso al interior de algunos países sobre el respeto pleno por los derechos de las minorías sexuales no puede ser considerado como un argumento válido para negarles o restringirles sus derechos humanos o para perpetuar y reproducir la discriminación histórica y estructural que estas minorías han sufrido. El hecho de que esta pudiera ser materia controversial en algunos sectores y países, y que no sea necesariamente materia de consenso no puede conducir al Tribunal a abstenerse de decidir, pues al hacerlo debe remitirse única y exclusivamente a las estipulaciones de las obligaciones internacionales contraídas por decisión soberana de los Estados a través de la Convención Americana (párr. 92). [Subrayas añadidas].

Así las cosas, es posible observar que la Corte Interamericana no ha hecho uso de la doctrina del margen de apreciación de la misma forma y con igual frecuencia que el Tribunal Europeo. Además, aunque hay casos en que la Corte debe reconocer la facultad que tienen las autoridades estatales para fijar el alcance de determinados elementos de los derechos, no por ello cabe sostener que esto sea una aplicación equivalente de la doctrina del margen de apreciación del Tribunal Europeo.

Por otro lado, el principio de interpretación evolutiva de los tratados de derechos humanos sí ha sido acogido por la Corte. Este principio, o herramienta, supone que si las circunstancias sociales han cambiado, la protección efectiva de los derechos ha de amoldarse a la nueva situación (Pastor Ridruejo, 2007, p. 247). El Tribunal Europeo introdujo esta idea en su jurisprudencia bajo el argumento que el Convenio Europeo es "un instrumento vivo que ha de interpretarse a la luz de las condiciones de hoy" (TEDH, caso Marckx vs. Bélgica, 1979). La Corte Interamericana ha utilizado justamente esta misma definición, ${ }^{26}$ arguyendo que es compatible con el artículo 29 de la Convención Americana, en el que se consagran las pautas interpretativas específicas de este tratado.

De lo anterior se desprende la manera en que las doctrinas del margen de apreciación y la in-

26 Ver por ejemplo: CORTE IDH, casos: Hermanos Gómez Paquiyauri vs. Perú. Fondo, Reparaciones y Costas. Sentencia de 8 de julio de 2004. Serie C n. ${ }^{\circ} 110$, párr. 165; "Niños de la Calle” (Villagrán Morales y otros) vs. Guatemala. Fondo. Sentencia de 19 de noviembre de 1999. Serie C n. ${ }^{\circ}$ 63, párr. 193; CORTE IDH. Caso de la Comunidad Mayagna (Sumo) Awas Tingni vs. Nicaragua. Fondo, Reparaciones y Costas. Sentencia de 31 de agosto de 2001. Serie $C$ n. ${ }^{\circ} 79$, párrafo 148; CORTE IDH. Caso de las Masacres de Ituango vs. Colombia. Excepción Preliminar, Fondo, Reparaciones y Costas. Sentencia de 1 de julio de 2006. Serie C n. ${ }^{\circ}$ 148, párr. 155. 
terpretación evolutiva se oponen. Para esta última herramienta es indispensable que, si los tiempos han cambiado, el alcance de los tratados de derechos humanos se acople a estas nuevas circunstancias. Para su aplicación, no se requiere la existencia de consenso entre los Estados o que la sociedad específica de cada uno de ellos esté de acuerdo, ya que puede suceder que estas concepciones sean las que están generando la vulneración de los derechos.

Acoger la técnica de la interpretación evolutiva por encima de la doctrina del margen de apreciación implica, entonces, determinar que, si bien el espíritu inicial del artículo 17.2 de la Convención era consagrar el derecho al matrimonio únicamente para parejas heterosexuales, este instrumento no es estático. La interpretación de las normas de la Convención Americana debe evolucionar y ajustarse a las condiciones de vida actuales.

Ahora bien, justamente las condiciones de vida actuales muestran que la comprensión de la homosexualidad ha evolucionado con el tiempo. En un comienzo los homosexuales fueron rechazados socialmente de manera radical, pero con el paso de tiempo, gracias a movilizaciones sociales, la tolerancia se ha incrementado tanto social como jurídicamente; incluso aunque la discriminación no haya sido erradicada por completo.

Como se señaló en la introducción de este escrito, cada vez más Estados reconocen el derecho de las parejas del mismo sexo a contraer matrimonio, ya sea mediante decisiones de autorida- des judiciales ${ }^{27}$ o mediante trámite legislativo. ${ }^{28}$ Además, entes internacionales como la Organización de Estados Americanos ${ }^{29}$ y la Organización de las Naciones Unidas, ${ }^{30}$ han expedido varias resoluciones que velan por garantizar en mayor medida los derechos humanos de aquellas personas que han sido discriminadas en razón de su orientación sexual o su identidad de género. Por último, es relevante también la reunión de varios expertos en materia de derechos humanos y discriminación por orientación sexual, quienes expidieron los denominados Principios de Yogyakarta, ${ }^{31}$ sobre la aplicación de la legislación internacional de derechos humanos en relación con la orientación sexual y la identidad de género.

A partir de esta evolución, las parejas del mismo sexo actualmente reclaman fervientemente ser tratados de igual manera que las parejas heterosexuales. De esta forma, aunque así pudo

27 Por ejemplo: Brasil, México, Estados Unidos.

28 Por ejemplo: Francia, Uruguay, Nueva Zelanda.

29 OEA. AG/RES. 2653 (XLI-O/11), Derechos humanos, orientación sexual e identidad de género, aprobada en la cuarta sesión plenaria, celebrada el 7 de junio de 2011; OEA AG/RES. 2504 (XXXIX-O/09), Derechos humanos, orientación sexual e identidad de género, aprobada en la cuarta sesión plenaria, celebrada el 4 de junio de 2009.

30 ONU, Asamblea General. Declaración sobre derechos humanos, orientación sexual e identidad de género, $A / 63 / 635,22$ de diciembre de 2008; ONU. Declaración conjunta para poner alto a los actos de violencia, y a las violaciones de derechos humanos relacionadas, dirigidos contra las personas por su orientación sexual e identidad de género, presentada por Colombia en el $16^{\circ}$ período de sesiones del Consejo de Derechos Humanos de las Naciones Unidas, 22 de marzo de 2011. ONU, Consejo de Derechos Humanos. Resolución respecto a derechos humanos, orientación sexual e identidad de género, $A$ / HRC/17/L.9/Rev.1, 15 de junio de 2011.

31 Principios de Yogyakarta. Adoptados tras la celebración de una reunión de especialistas realizada en Yogyakarta, Indonesia, del 6 al 9 de noviembre de 2006. 
considerarse en otros tiempos, actualmente el artículo 17.2 de la Convención Americana no puede interpretarse en un sentido en el que se excluye a un grupo determinado de personas del disfrute de un derecho, en razón de su orientación sexual.

Este tipo de consideraciones, y la prevalencia de la interpretación evolutiva por encima de la doctrina del margen de apreciación dentro de la jurisprudencia interamericana, sin duda contribuirá a que la Corte Interamericana realice una interpretación más amplia que la del Tribunal Europeo sobre el derecho al matrimonio.

Como lo estableció la Corte Interamericana en el caso Atala:

en el marco de las sociedades contemporáneas se dan cambios sociales, culturales e institucionales encaminados a desarrollos más incluyentes de todas las opciones de vida de sus ciudadanos, lo cual se evidencia en la aceptación social de parejas interraciales, las madres o padres solteros o las parejas divorciadas, las cuales en otros momentos no habían sido aceptadas por la sociedad. En este sentido, el Derecho y los Estados deben ayudar al avance social, de lo contrario se corre el grave riesgo de legitimar y consolidar distintas formas de discriminación violatorias de los derechos humanos. (Corte IDH, Atala Riffo y niñas vs. Chile, 2012, párr. 120).

\section{Interpretación acorde al principio pro homine}

Como se expresó anteriormente, además de las pautas usuales de interpretación del derecho internacional público, la Convención Americana consagra en su artículo 29 algunas pautas adicionales.

De este artículo, la Corte Interamericana ha extraído el denominado principio pro homine, el cual ha sido definido como:

un criterio hermenéutico (...), en virtud del cual se debe acudir a la norma más amplia, o a la interpretación más extensiva, cuando se trata de reconocer derechos protegidos e, inversamente, a la norma o a la interpretación más restringida cuando se trata de establecer restricciones permanentes al ejercicio de los derechos o su suspensión extraordinaria (Pinto, 1997, p. 1).

Así, en casos como Ricardo Canese vs. Paraguay (2004) y Vélez Loor vs. Panamá (2010) recordó la Corte que en virtud del principio pro homine, es necesario que cuando entren en conflicto dos normas o dos maneras de interpretar una norma, prevalezca aquella que más favorezca los derechos de la persona humana.

Incluso, en el caso de la Masacre de Mapiripán vs. Colombia (2005), al evaluar la responsabilidad internacional del Estado colombiano por las acciones de fuerzas paramilitares, la Corte hace una interpretación conjunta entre el principio pro homine y la interpretación evolutiva, en la que se sugiere que ambas herramientas son interdependientes. Básicamente, señala la Corte que para lograr una efectiva interpretación que sea favorable a los derechos de la persona humana, es indispensable interpretar las normas de acuerdo con las condiciones de vida actua- 
les. Así se pronunció la Corte en el caso de la Masacre de Mapiripán:

Asimismo, la Corte ha señalado, al igual que la Corte Europea de Derechos Humanos, que los tratados de derechos humanos son instrumentos vivos, cuya interpretación tiene que acompañar la evolución de los tiempos y las condiciones de vida actuales. Tal interpretación evolutiva es consecuente con las reglas generales de interpretación consagradas en el artículo 29 de la Convención Americana, así como las establecidas por la Convención de Viena sobre el Derecho de los Tratados. En este sentido, al interpretar la Convención debe siempre elegirse la alternativa más favorable para la tutela de los derechos protegidos por dicho tratado, según el principio de la norma más favorable al ser humano" (párr. 106). [Subrayas añadidas].

En los acápites anteriores se demostró, por un lado, que mediante una interpretación literal, sistemática y teleológica del derecho al matrimonio consagrado en el artículo 17.2 de la Convención Americana, este está establecido únicamente para parejas heterosexuales y, por otro, que también puede hacerse otra interpretación de la norma mediante la utilización del principio de interpretación evolutiva.

La necesidad de utilizar la interpretación evolutiva por encima de la literal, sistemática y teleológica, en un caso concreto sobre matrimonio de parejas homosexuales, incrementa al tener en cuenta el principio pro homine descrito anteriormente.

Ambas formas de interpretación son aceptables a la luz de las pautas interpretativas del derecho internacional público y del artículo 29 de la Convención Americana. Sin embargo, una de ellas fomenta que continúe existiendo la aplicación de un trato diferenciado a las parejas del mismo sexo, mientras que la otra reconoce que la percepción sobre el tema está cambiando, que cada vez más Estados a nivel mundial reconocen este cambio, y que por ello mantener este trato diferenciado entre parejas heterosexuales y parejas homosexuales es cada vez menos justificable. Así, de acuerdo con el principio pro homine, debe prevalecer la interpretación evolutiva que pueda realizarse del artículo 17.2 de la Convención Americana.

\section{E. Igualdad y no discriminación como norma ius cogens}

Otro elemento que será relevante para la Corte Interamericana, en cuanto al matrimonio de parejas del mismo sexo, es que esta ha determinado que el derecho a la igualdad y no discriminación es de carácter ius cogens. Por ende, cabe sostener que este derecho tiene una preponderancia mayor que algunos de los otros derechos dentro del Sistema Interamericano.

De conformidad con el artículo 53 de la Convención de Viena sobre el Derecho de los Tratados, las normas ius cogens -o jus cogens- son normas imperativas de derecho internacional que son "aceptada[s] y reconocida[s] por la comunidad internacional de Estados en su conjunto como norma[s] que no admite[n] acuerdo en contrario y que sólo puede[n] ser modificada[s] por una norma ulterior de derecho internacional que tenga el mismo carácter". 
Según lo ha establecido el Tribunal Europeo de Derechos Humanos y lo ha reiterado la Corte Interamericana, las implicaciones de determinar que una norma es de carácter ius cogens son las siguientes:

el reconocimiento de que la norma es jerárquicamente superior con respecto a cualquier norma de derecho internacional, exceptuando otras normas de jus cogens; en caso de conflicto, tendría la primacía la norma de jus cogens frente a cualquier otra norma de derecho internacional, y sería nula o carecería de efectos legales la disposición que sea contraria a la norma imperativa (Corte IDH, OC-18/03, 2003).

La Corte Interamericana afirmó por primera vez que el derecho a la igualdad y no discriminación es de carácter ius cogens en la Opinión Consultiva 18 sobre la condición jurídica y los derechos de los migrantes indocumentados. Así se pronunció la Corte:

este Tribunal considera que el principio de igualdad ante la ley, igual protección ante la ley y no discriminación, pertenece al jus cogens, puesto que sobre él descansa todo el andamiaje jurídico del orden público nacional e internacional y es un principio fundamental que permea todo ordenamiento jurídico.

Hoy día no se admite ningún acto jurídico que entre en conflicto con dicho principio fundamental, no se admiten tratos discriminatorios en perjuicio de ninguna persona, por motivos de género, raza, color, idioma, religión o convicción, opinión política o de otra índole, origen nacional, étnico o social, nacionalidad, edad, situación económica, patrimonio, estado civil, nacimiento o cualquier otra condición. Este principio (igualdad y no discriminación) forma parte del derecho internacional general. En la actual etapa de la evolución del derecho internacional, el principio fundamental de igualdad y no discriminación ha ingresado en el dominio del jus cogens (párr. 101).

Este criterio determinado en la Opinión Consultiva 18 ha sido reiterado por la Corte en casos contenciosos, tales como Yatama vs. Nicaragua (2005), el de la Comunidad Indígena Xákmok Kásek vs. Paraguay (2010) y Atala Riffo y niñas vs. Chile.

Ahora bien, es cierto que el que la Corte Interamericana haya declarado que el derecho a la igualdad y no discriminación es de carácter ius cogens puede ser motivo de debate. Esto, principalmente porque existe controversia hoy en día no solo sobre la definición exacta de lo que constituye una norma ius cogens, sino también sobre quién está legitimado para hacer tal declaración y con base en cuáles fundamentos.

Con todo, lo importante para el presente escrito es que, dentro de sus decisiones, la Corte Interamericana ha dado una preponderancia especial al derecho a la igualdad y no discriminación. Por ende, esta tendencia debe ser tenida en cuenta al analizar un caso de matrimonio de parejas del mismo sexo.

El que el derecho a la igualdad y no discriminación sea una norma ius cogens dentro del Sistema Interamericano, implica que la Corte Interamericana no necesariamente evaluará con la misma levedad que el Tribunal Europeo la posible existencia de una discriminación, por 
no permitir a parejas del mismo sexo contraer matrimonio.

Teniendo en cuenta lo esbozado en el acápite anterior sobre la herramienta interpretativa que ha privilegiado la Corte Interamericana, es poco probable que por lo que indica la mera interpretación literal de una norma, la Corte ignore la existencia del trato diferenciado, hoy en día injustificado, que se da a las parejas del mismo sexo en cuanto al matrimonio.

Finalmente, y aunado a esta preponderancia especial que tiene el derecho a la igualdad y no discriminación dentro del Sistema Interamericano, es importante tener en cuenta un último elemento. Como se señaló al principio de este acápite, ciertamente la redacción literal del derecho al matrimonio dentro de la Convención Americana es similar a la del Convenio Europeo. Sin embargo, hay una diferencia importante que no debe dejarse de lado, y que se relaciona específicamente con el derecho a la igualdad y no discriminación, por lo que se consideró pertinente reservarla para esta sección del escrito.

El artículo 17.2 de la Convención Americana establece explícitamente que "se reconoce el derecho del hombre y la mujer a contraer matrimonio y a fundar una familia si tienen la edad y las condiciones requeridas para ello por las leyes internas, en la medida en que estas no afecten al principio de no discriminación establecido en esta Convención (artículo 17.2). [Subrayas añadidas].

De esta forma, la norma que consagra el derecho al matrimonio en el Sistema Interamericano no solo está protegida por la prohibición de discriminación general contenida en el artículo 1.1 de la Convención, sino que además incluye esta prohibición de forma explícita e independiente. Así, es razonable asumir también que este elemento, aunado a la condición de norma ius cogens que tiene el derecho a la igualdad y no discriminación, serán criterios importantes que sin duda incidirán en la eventual decisión de la Corte Interamericana.

\section{CONCLUSIONES}

Como se planteó en la introducción de este escrito, la pregunta que se pretendía responder mediante el análisis anterior es si la Corte Interamericana realizará la misma interpretación del derecho al matrimonio que el Tribunal Europeo, al enfrentarse a una pretensión relacionada con el matrimonio de parejas del mismo sexo.

El debate existe por varias razones. Principalmente, debido a que dentro del Sistema Interamericano no se ha fijado el alcance del derecho al matrimonio ni ha habido un pronunciamiento concreto sobre matrimonio de parejas homosexuales, no solo es necesario sino razonable prever que la Corte Interamericana hará referencia a lo dispuesto al respecto por otros tribunales internacionales. Esto, en virtud de la herramienta interpretativa del corpus iuris de derechos humanos.

Por lo anterior, se torna relevante el caso Schalk y Kopf vs. Austria del Tribunal Europeo de De- 
rechos Humanos. En este caso, mediante una interpretación literal, sistemática y teleológica, junto con el uso de la doctrina del margen nacional de apreciación, se concluyó que el derecho al matrimonio dentro del Convenio Europeo está consagrado únicamente para parejas de diferente sexo, y que el que un Estado no lo permitiera para parejas del mismo sexo no constituía una vulneración de este derecho ni una discriminación.

Adicionalmente, la interpretación literal, sistemática y teleológica que aplicó el Tribunal Europeo al artículo 12 del Convenio Europeo es igualmente predicable del artículo 17.2 de la Convención Americana; es por ello que surge la cuestión sobre si el pronunciamiento que haga la Corte Interamericana será igual a la del Tribunal Europeo.

Con base en lo esbozado en el quinto capítulo de este escrito, cabe concluir que lo más probable es que la Corte Interamericana haga una interpretación distinta al Tribunal Europeo sobre el derecho al matrimonio. Esto se debe a tres razones principales relacionadas, básicamente, con particularidades del Sistema Interamericano que lo diferencian del Sistema Europeo.

Primera, que la Corte Interamericana ha aplicado reiteradamente el principio de interpretación evolutiva, según el cual los tratados de derechos humanos son instrumentos vivos que deben interpretarse a la luz de las condiciones de vida actuales. Por esto, debido a que la noción de matrimonio ha cambiado, que cada vez más Estados permiten el matrimonio entre parejas del mismo sexo, y que distintos entes internacionales se han esforzado por eliminar la violación de derechos humanos en razón de la orientación sexual y la identidad de género, es necesario interpretar el derecho al matrimonio de acuerdo con estos elementos.

Es cierto que el Tribunal Europeo decidió no aplicar el principio de interpretación evolutiva y prefirió, por el contrario, tener en cuenta elementos que configuran la doctrina del margen nacional de apreciación: el consenso regional y las características sociales específicas de los países. No obstante, la Corte Interamericana no ha aplicado esta doctrina al igual que el Tribunal Europeo, y además ha desechado explícitamente la posibilidad de tomar como criterios interpretativos los elementos que la configuran. Por ende, crece la importancia de aplicar la interpretación evolutiva.

Segunda y sumado a lo anterior, la Corte Interamericana también ha enfatizado la necesidad de interpretar las normas de acuerdo con el principio pro homine, según el cual debe acogerse la norma o la interpretación de la misma que más favorece los derechos de la persona humana. Por ende, aunque tanto la interpretación literal, sistemática y teleológica como la evolutiva son aplicables, debe optarse por aquella que resulte más garantista para las parejas homosexuales.

Tercera, puede afirmarse con facilidad que la Corte Interamericana no desestimará la posible existencia de una vulneración del derecho a la igualdad y no discriminación con la misma facilidad que lo hizo el Tribunal Europeo. Esto, por 
cuanto dentro del Sistema Interamericano este derecho es de carácter ius cogens, lo que conduce a que tenga una preponderancia mayor que algunos de los demás derechos convencionales.

De esta forma, aunque el derecho al matrimonio inicialmente se concebía para parejas heterosexuales, hoy en día esto genera un trato diferenciado, cuya justificación corresponde analizar a la Corte misma. Por ende, si bien parece que entraran en conflicto estos dos derechos, debe prevalecer el derecho a la igualdad y no discriminación. Además, esta preponderancia especial se magnifica, en la medida en que el artículo 17.2 de la Convención Americana consagra explícitamente la prohibición de discriminación dentro de su redacción.

Así las cosas, es cierto que los sistemas de derecho internacional de los derechos humanos se nutren entre sí, y es por esto que la Corte Interamericana y el Tribunal Europeo muchas veces suelen tener tendencias similares. En materia de orientación sexual ha sido así, pues la única vez que la Corte Interamericana se enfrentó a la materia, en el caso Atala Riffo y niñas vs. Chile, construyó su argumentación según la jurisprudencia del Tribunal Europeo.

Sin embargo, en materia del derecho al matrimonio de parejas del mismo sexo, es razonable asumir que las tendencias van a ser distintas. Debido a las particularidades del Sistema Interamericano descritas anteriormente, es altamente probable que la Corte interprete el derecho al matrimonio de una manera más amplia, en el sentido que este sea predicable no solo para parejas heterosexuales sino también de parejas homosexuales.

La eventual decisión de la Corte, sea cual sea su postura, tendrá un efecto significativo dentro del contexto socio jurídico de los países partes de la Convención Americana en la medida en que, como se estableció al inicio de este escrito, las decisiones de la Corte son vinculantes para estos Estados. De esta forma, si bien con el paso del tiempo la discriminación por orientación sexual o identidad de género cada vez se reduce un poco más dentro de cada uno de los Estados, si la decisión de la Corte Interamericana en efecto llega a ser en el sentido acá expuesto, este será un avance significativo en materia de derechos de la población LGBTI.

\section{Referencias}

Barbosa Delgado, F. (2011). Los límites a la doctrina del margen nacional de apreciación en el Tribunal Europeo y la Corte Interamericana de Derechos Humanos: intervención judicial en torno a ciertos derechos de las minorías étnicas y culturales. Recuperado de http:// revistas.uexternado.edu.co/index.php?journ al=derest $\&$ page $=$ article $\& o p=$ view $\&$ path $\% 5 B$ $\% 5 \mathrm{D}=2881$

Barbosa Delgado, F. (2012). El margen nacional de apreciación y sus límites en la libertad de expresión: análisis comparado de los sistemas europeo e interamericano de derechos humanos. Bogotá: Universidad Externado de Colombia. 
Barbosa Delgado, F. R. (2013). El margen nacional de apreciación en el derecho internacional de los derechos humanos: entre el Estado de Derecho y la sociedad democrática. En P. Acosta Alvarado y M. Núñez Poblete (Edits.), El margen de apreciación en el SIDH: proyecciones regionales y nacionales. México D. F.: Instituto de Investigaciones Jurídicas de la UNAM.

Comisión Interamericana de Derechos Humanos. (2013). Reglamento de la Comisión Interamericana de Derechos Humanos. Aprobado por la Comisión en su $137^{\circ}$ período ordinario de sesiones, celebrado del 28 de octubre al 13 de noviembre de 2009; y modificado el 2 de septiembre de 2011 y en su $147^{\circ}$ período ordinario de sesiones, celebrado del 8 al 22 de marzo de 2013, para su entrada en vigor el $1^{\circ}$ de agosto de 2013.

Consejo de Europa. (1950). Convenio Europeo para la protección de los Derechos Humanos y las Libertades Fundamentales, adoptado por el Consejo de Europa el 4 de noviembre de 1950.

Corte Interamericana de Derechos Humanos. Caso Herrera Ulloa vs. Costa Rica, (Excepciones preliminares, fondo, reparaciones y costas). Sentencia del 2 de julio de 2004. Serie C n. 107.

Corte Interamericana de Derechos Humanos. Caso Ricardo Canese vs. Paraguay. (Fondo, reparaciones y costas). Sentencia del 31 de agosto de 2004. Serie C n. ${ }^{\circ} 111$.
Corte Interamericana de Derechos Humanos. Caso de la Masacre de Mapiripán vs. Colombia. (Fondo). Sentencia del 15 de septiembre de 2005. Serie C n. 134.

Corte Interamericana de Derechos Humanos. (2009). Reglamento de la Corte Interamericana de Derechos Humanos. Aprobado por la Corte en su LXXXV Período Ordinario de Sesiones, celebrado del 16 al 28 de noviembre de 2009.

Corte Interamericana de Derechos Humanos. Caso Artavia Murillo y otros ("Fecundación in vitro") vs. Costa Rica. (Excepciones Preliminares, Fondo, Reparaciones y Costas). Sentencia 28 de noviembre de 2012 . Serie $\mathrm{C}$ n. ${ }^{\circ}$ 257.

Corte Interamericana de Derechos Humanos. Caso Atala Riffo y niñas vs. Chile. (Excepciones Preliminares, Fondo y Costas). Sentencia de 24 de febrero de 2012. Serie C n. 239.

Corte Interamericana de Derechos Humanos. Caso Cabrera García y Montiel Flores vs. México. (Excepciones Preliminares, Fondo, Reparaciones y Costas). Sentencia del 26 de noviembre de 2006. Serie C n. ${ }^{\circ} 220$.

Corte Interamericana de Derechos Humanos. Caso Castañeda Gutman vs. Estados Unidos Mexicanos. (Excepciones Preliminares, Fondo, Reparaciones y Costas). Sentencia del 6 de Agosto de 2008. Serie C n. 184.

Corte Interamericana de Derechos Humanos. Caso Chaparro Álvarez y Lapo Iñiguez vs. 
Ecuador. (Excepciones Preliminares, Fondo, Reparaciones y Costas). Sentencia de 25 de noviembre de 2007. Serie C n. ${ }^{\circ} 170$.

Corte Interamericana de Derechos Humanos. Caso Comunidad Indígena Xákmok Kásek vs. Paraguay. (Fondo, Reparaciones y Costas). Sentencia de 24 de agosto de 2010. Serie C. n. ${ }^{\circ} 214$.

Corte Interamericana de Derechos Humanos. Caso Contreras y otros vs. El Salvador. (Fondo, Reparaciones y Costas). Sentencia de 31 de agosto de 2011. Serie C n. ${ }^{\circ} 232$.

Corte Interamericana de Derechos Humanos. Caso de la Comunidad Mayagna (Sumo) Awas Tingni vs. Nicaragua. Fondo, Reparaciones y Costas. Sentencia de 31 de agosto de 2001. Serie $\mathrm{C} n .^{\circ} 79$.

Corte Interamericana de Derechos Humanos. Caso de las Masacres de Ituango vs. Colombia. (Excepción Preliminar, Fondo, Reparaciones y Costas). Sentencia de 1 de julio de 2006. Serie C n. ${ }^{\circ} 148$.

Corte Interamericana de Derechos Humanos. Caso de los "Niños de la Calle" (Villagrán Morales y otros) vs. Guatemala. (Fondo). Sentencia de 19 de noviembre de 1999. Serie C n. ${ }^{\circ}$ 63.

Corte Interamericana de Derechos Humanos. Caso de los Hermanos Gómez Paquiyauri vs. Perú. (Fondo, Reparaciones y Costas). Sentencia de 8 de julio de 2004. Serie C n. ${ }^{\circ} 110$.
Corte Interamericana de Derechos Humanos. Caso Gelman vs. Paraguay. (Fondo y Reparaciones). Sentencia de 24 de febrero de 2011.

Corte Interamericana de Derechos Humanos. Caso Ricardo Canese vs. Paraguay. (Fondo, Reparaciones y Costas). Sentencia de 31 de agosto de 2004. Serie C n. ${ }^{\circ} 111$.

Corte Interamericana de Derechos Humanos. Caso Velásquez Rodríguez vs. Honduras. (Fondo). Sentencia de 29 de julio de 1988. Serie $\mathrm{C} n .^{\circ} 4$.

Corte Interamericana de Derechos Humanos. Caso Yatama vs. Nicaragua. (Excepciones preliminares, Fondo, Reparaciones y Costas). Sentencia del 23 de junio de 2005. Serie C n. ${ }^{\circ} 127$.

Corte Interamericana de Derechos Humanos. Opinión Consultiva OC-17/02. Condición jurídica y derechos humanos del niño. 28 de agosto de 2002. Serie A n. ${ }^{\circ} 17$.

Corte Interamericana de Derechos Humanos. Opinión Consultiva OC-18/03. Condición Jurídica y derechos de los migrantes indocumentados. 17 de septiembre de 2003. Serie A n. ${ }^{\circ}$ 18.

Corte Interamericana de Derechos Humanos. Opinión Consultiva OC-4/84. Propuesta de modificación a la Constitución Política de Costa Rica relacionada con la naturalización. 19 de enero de 1984. Serie A n. ${ }^{\circ} 04$. 
Fáundez Ledesma, H. (2004). El sistema interamericano de protección de derechos humanos: aspectos institucionales y procesales. (3 ed.). San José: Instituto Interamericano de Derechos Humanos.

Hitters, J. C. (2013). Un avance en el control de convencionalidad. (El efecto erga omnes de las sentencias de la Corte Interamericana). Revista de Direito Internacional dos Direitos Humanos, 1(1), 100-115. Recuperado de http://www.revistadidh.com.br/ojs/index. php/REDIDH/article/view/1

Noseda Gutiérrez, J. (diciembre de 2012). Muchas formas de transexualidad: diferencias entre ser una mujer transexual y una mujer transgénero. Revista de Psicología, 21(2), 7-30.

Núñez Poblete, M. (17 de noviembre de 2012). Sobre la doctrina del margen de apreciación nacional. La experiencia latinoamericana confrontada y el thelos constitucional de una técnica de adjudicación del derecho internacional de los derechos humanos. Recuperado de http://biblio.juridicas.unam.mx/ libros/7/3160/6.pdf

Organización de Estados Americanos (2009). AG/RES. 2504 (XXXIX-0/09). Derechos humanos, orientación sexual e identidad de género, aprobada en la cuarta sesión plenaria, celebrada el 4 de junio de 2009.

Organización de Estados Americanos. (2009). AG/RES. 2504 (XXXIX-0/09). Derechos hu- manos, orientación sexual e identidad de género, aprobada en la cuarta sesión plenaria, celebrada el 4 de junio de 2009.

Organización de Estados Americanos. (2011). AG/RES. 2653 (XLI-O/11). Derechos humanos, orientación sexual e identidad de género, aprobada en la cuarta sesión plenaria, celebrada el 7 de junio de 2011.

Organización de los Estados Americanos. (1969). Convención Americana sobre Derechos Humanos, suscrita en la Conferencia Especializada Interamericana sobre Derechos Humanos. San José, Costa Rica, 7-22 de noviembre de 1969.

Organización de Naciones Unidas, Asamblea General. (22 de diciembre de 2008). Declaración Universal sobre derechos humanos, orientación sexual e identidad de género, A/63/635.

Organización de Naciones Unidas, Asamblea General. (Diciembre 10 de 1948). Declaración Universal de Derechos Humanos.

Organización de Naciones Unidas, Consejo de Derechos Humanos. (15 de junio de 2011). Resolución respecto a derechos humanos, orientación sexual e identidad de género, A/ HRC/17/L.9/Rev.1.

Organización de Naciones Unidas. (1969). Convención de Viena sobre el Derecho de los Tratados, adoptada por la Asamblea General de las Naciones Unidas en Viena el 23 de mayo 
de 1969. Entró en vigencia el 27 de enero de 1980.

Organización de Naciones Unidas. (22 de marzo de 2011). Declaración conjunta para poner alto a los actos de violencia, y a las violaciones de derechos humanos relacionadas, dirigidos contra las personas por su orientación sexual e identidad de género, presentada por Colombia en el $16^{\circ}$ período de sesiones del Consejo de Derechos Humanos de las Naciones Unidas.

Organización de Naciones Unidas. (17 de noviembre de 2011). Informe del Alto Comisionado de las Naciones Unidas para los Derechos Humanos. Leyes y prácticas discriminatorias y actos de violencia cometidos contra personas por su orientación sexual e identidad de género.

Pastor Ridruejo, J. A. (2007). La reciente jurisprudencia del Tribunal Europeo de Derechos Humanos: temas escogidos. Recuperado de http://www.ehu.es/cursosderechointernacionalvitoria/ponencias/pdf/2007/2007_8. pdf

Pinto, M. (1997). El principio pro homine. Criterios de hermenéutica y pautas para la regulación de los derechos humanos. En M. Abregú y C. Courtis (Comps.), La aplicación de los tratados sobre derechos humanos por los tribunales locales (pp. 3-32). Buenos Aires, Argentina: Editores del Puerto. Recuperado de http://www.corteidh.or.cr/tablas/20185.pdf
Principios de Yogyakarta. Adoptados tras la celebración de una reunión de especialistas realizada en Yogyakarta, Indonesia, del 6 al 9 de noviembre de 2006.

Tribunal Europeo de Derechos Humanos. Caso Clift vs. Reino Unido, (n. $\left.{ }^{\circ} 7205 / 07\right)$, sentencia de 13 de julio de 2010. Final, 22 de noviembre de 2010.

Tribunal Europeo de Derechos Humanos. Caso E.B. vs. Francia, (n. ${ }^{\circ}$ 43546/02), sentencia de 22 de enero de 2008.

Tribunal Europeo de Derechos Humanos. Caso Keegan vs. Irlanda, (n. $\left.{ }^{\circ} 16969 / 90\right)$, sentencia de 26 de mayo de 1994.

Tribunal Europeo de Derechos Humanos. Caso Kroon y otros vs. Países Bajos, (n. 18535/91), sentencia de 27 de octubre de 1994.

Tribunal Europeo de Derechos Humanos. Caso Marckx vs. Bélgica, (n. $\left.{ }^{\circ} 6833 / 74\right)$, sentencia de 13 de junio de 1979.

Tribunal Europeo de Derechos Humanos. Caso De Wilde, OOms et Wersyp vs. Bélgica, (n. ${ }^{\text {os }}$ 2832/66; 2835/66; 2899/66), 18 de junio de 1971.

Tribunal Europeo de Derechos Humanos. Caso Handyside vs. Reino Unido, (n. ${ }^{\circ}$ 5493/72), diciembre 7 de 1976.

Tribunal Europeo de Derechos Humanos. Caso Peck vs. Reino Unido, (n. $\left.{ }^{\circ} 44647 / 98\right)$, sen- 
tencia de 28 de enero de 2003. Final, 28 de abril de 2003.

Tribunal Europeo de Derechos Humanos. Caso Pretty vs. Reino Unido, (n. $\left.{ }^{\circ} 2346 / 02\right)$, sentencia de 29 de abril de 2002. Final, 29 de julio de 2002.

Tribunal Europeo de Derechos Humanos. Caso Salgueiro da Silva Mouta vs. Portugal, (n. ${ }^{\circ}$ 33290/96), sentencia de 21 de diciembre de 1999.
Tribunal Europeo de Derechos Humanos. Caso Schalk y Kopf vs. Austria, (n. $\left.{ }^{\circ} 30141 / 04\right)$, sentencia de 24 de junio de 2010.

Tribunal Europeo de Derechos Humanos. Caso Tyrer vs. Reino Unido, (n. $\left.{ }^{\circ} 5856 / 72\right)$, sentencia de 25 de abril de 1978.

Tribunal Europeo de Derechos Humanos. Karner vs. Austria, (n. $\left.{ }^{\circ} 40016 / 98\right)$, sentencia de 24 de julio de 2003. 